\title{
A STUDY OF THE POSSIBILITY OF COLD ENERGY UTILIZATION OF THE DEPTHS OF YEMEN REGIONAL SEA WATERS
}

\author{
Abdullah Ahmed Ba-Raadi \\ E.mail:Abdullah_raadi@yahoo.com
}

(Received July 22, 2009 Accepted Sebtember 24, 2009).

The results of our research work point to the possibility of introducing a new source of energy added to the other sources of renewable energy prevailing in Yemen. That is the energy of the cold waters at the depth of the sea (Exergy of cold water) in the Yemeni region of which the temperature reaches $2.6^{\circ} \mathrm{C}$ at $2400 \mathrm{~m}$ deep.

Three maps were identified and put for some astronomical sites of Yemeni regional waters of Aden gulffor the objective of their study. The physicothermal data relating to water surface up to $2400 \mathrm{~m}$ deep were studied and analyzed in order to define the sort of cooling media which can be used in the technology of this energy source.

For that purpose, the gases of Freon were chosen: R40, R142a, R22, R12, $\mathrm{Cl}_{2}$ and the sea cold water depths $\mathrm{H}_{2} \mathrm{O}_{S C W}$. The study of the physical, therodynemical, hydrocrystalline and gaseous properties of these media make us able to put a suggestion for three individual systems working by the closed physico-thermal circle and combined with the temperature of the deep sea waters for each working medium. These suggested systems are as the following: The first system for air conditioning is working on the gaseous hydrocrysalline method and uses the media of $\mathrm{Cl}_{2}, \mathrm{R} 40$, RI42a, R22, and R12. The second system for air conditioning is working on the all water system and uses the medium $\mathrm{H}_{2} \mathrm{O}_{S C W}$. The third system is working on the gaseous hydrocrystalline method of sea water desalination and uses the media of $\mathrm{Cl}_{2}, \mathrm{R} 40, \mathrm{R} 142 a, \mathrm{R} 22, \mathrm{R} 12$. Depending on the mentioned above, we conclude that the second system is the least energy consumption and environmentally pure due to its direct use of the cold sea waters as a cooling medium.

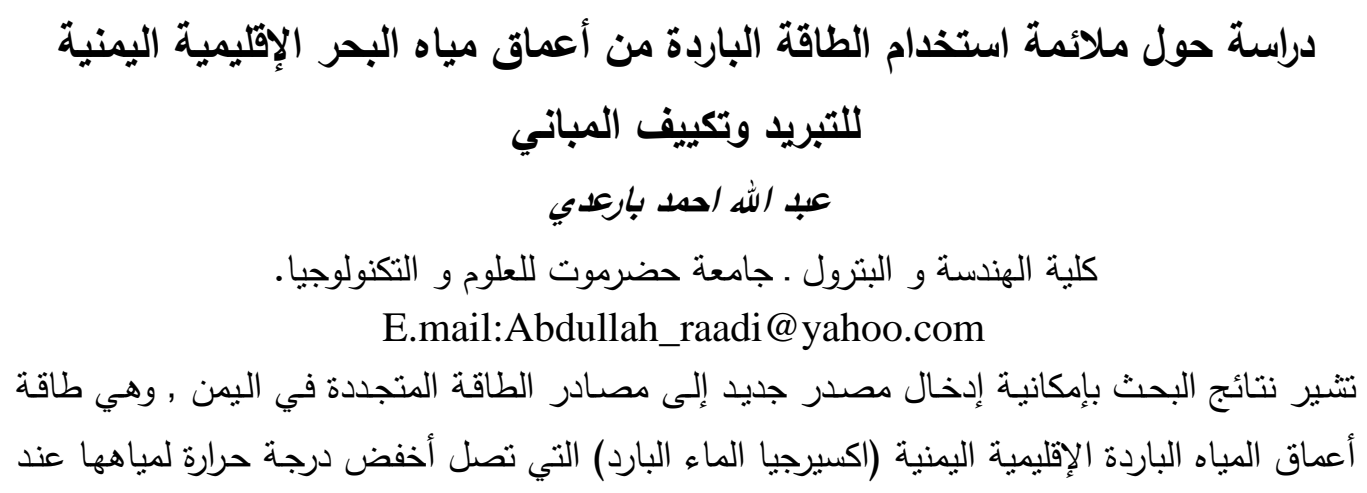


عمق 2400m إلى حوالي 2.6\% $2 .{ }^{\circ}$, حيث تمّ تحديد ووضع ثلاث خرائط لبعض المواقع الفلكية لأعماق

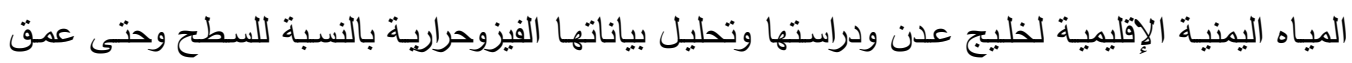
ل 2400m لذلك تم اختيار غازات الفريون : R12,R22,R142a,R40 والكلور إذ من خلال دراسة خواصها الفيزيائية والتزموديناميكية و الهيدروبلورية الغازية لهذه الوسائط

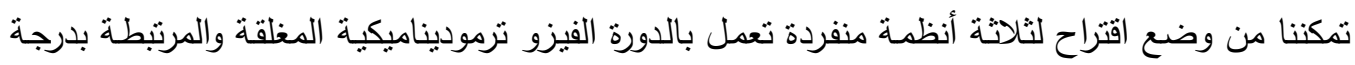
حرارة برودة مياه العمق لكل وسيط عامل وهي : النظام الأول لتكييف الهواء يعمل بالطريقة الهيدروبلورية

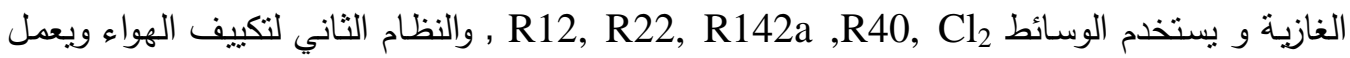
بالماء الثـامل النظام و يستخدم الوسبط Hew2 بالطريقة الهيدروبلورية الغازية ويستخدم وسائط التبريد Cl من أن النظام الثاني هو الأكثر نرشيدا للطاقة و الأنظف للبيئة نظرا لاستخدامه المباشر لهياه البحر الباردة كوسيط تبريد.

الكلمات المفتاحيه: مياه الأعماق الباردة , نظام الماء الثامل , طاقة متجددة , تكييف الهواء

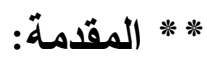

تغطى مياه البحار و المحيطات مساحات واسعة من سطح الكرة الأرضية و تقدر بحوالي 361 مليون

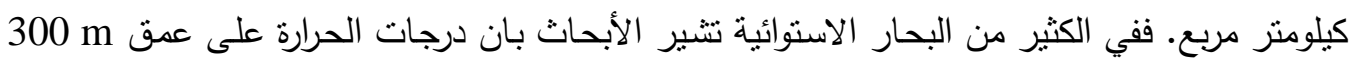

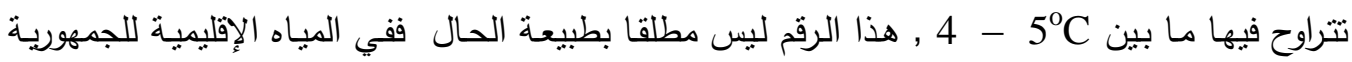
اليمنية تؤكد الدراسات بان : درجة الحرارة عند هذا العمق تعادل

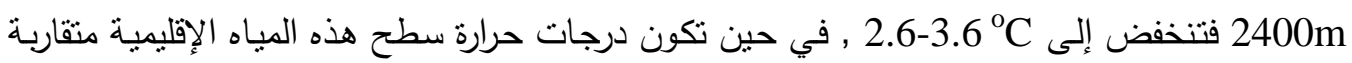

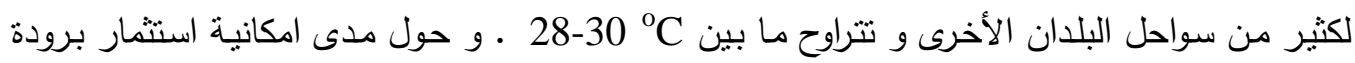

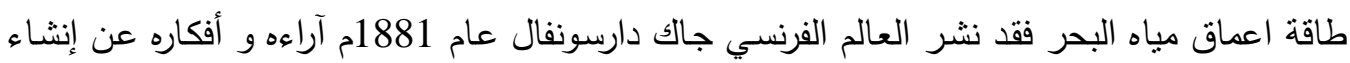
محطات تعمل على الفوارق في درجات الحرارة في البحار , وتبعه في ذلك كل من المهندس الفرنسي

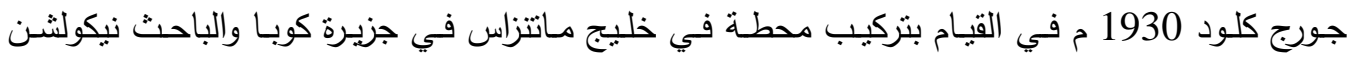

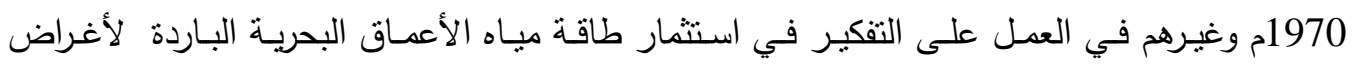

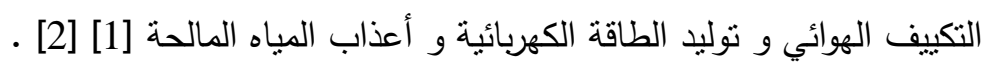

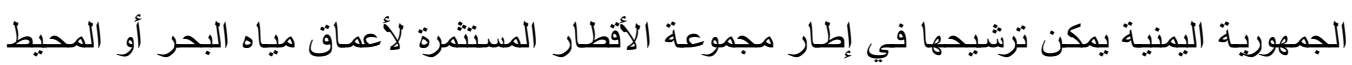
الباردة , فهي تقع فلكيا بين دائرتي عرض 12-20 درجة شمال خط الاستواء وخط طول 41 - 54 درجة شرق غرينتش , وتطل على كل من البحر العربي و المحيط الهندي و البحر الأحمر بسواحل 9

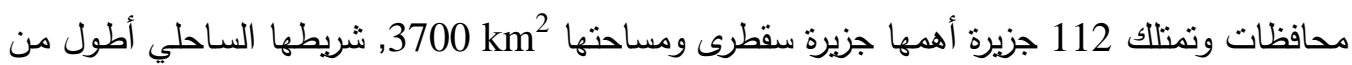




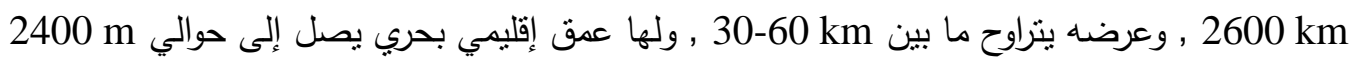
في الجزء الثرقي من خليج عدن الواقع على خط طول ما بين

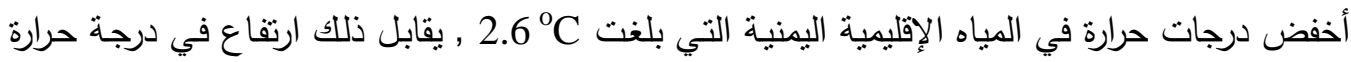

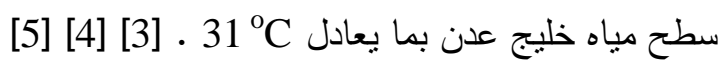

هذا البحث لا يناقش استثمار طاقة فارق الاتحدار الحراري بين السطح و عمق البحر , بل يتجه نحو الاستثمار المباشر لطاقة أو اكسبرجيا المياه الباردة المتواجدة في أعماق مياه البحر الإقليمية اليمنية ,

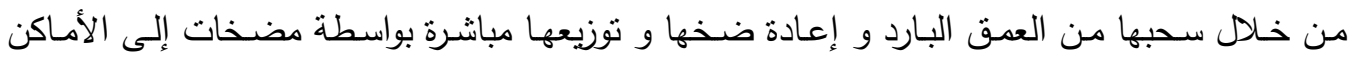

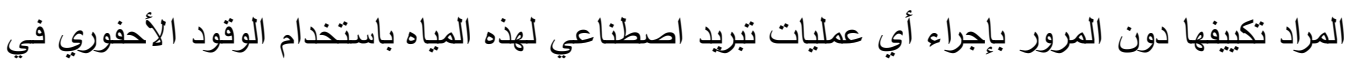

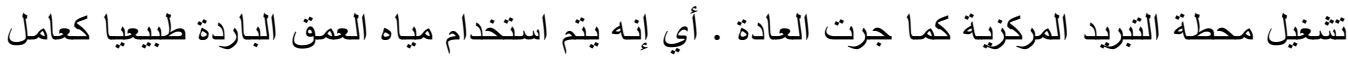

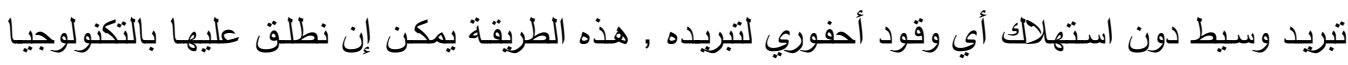
المتجددة لنظام الماء الثامل لتكييف الهواء , إذ أن التبادل الحراري في هذا النظام يتم مباشرة بين الثرد الهاء

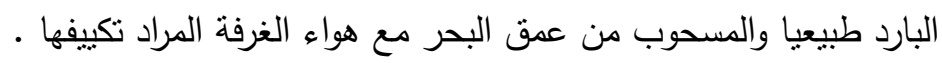

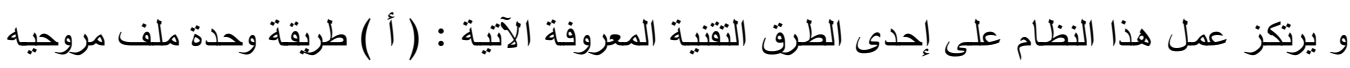

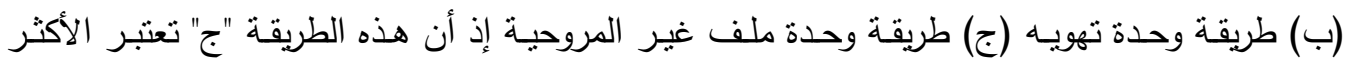

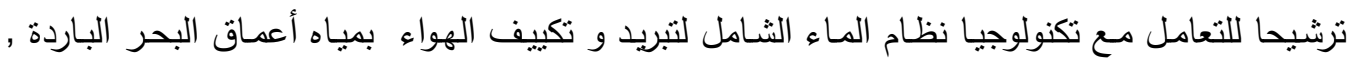
نظر لما لها من بساطة في التركيب و الاستخدام والصيانة .

إن نجاح عملية استثمار طاقة مياه الأعماق الإقليمية البحريـة الباردة اليمنية , ينطلب ضرورة تحديد

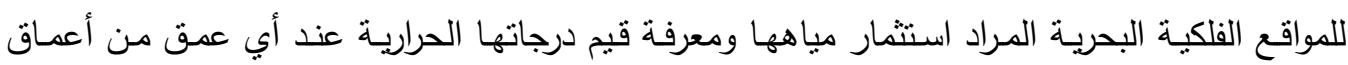

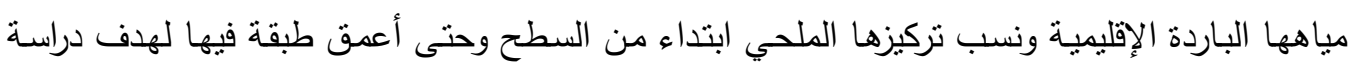

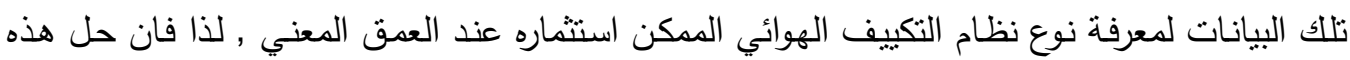
المسائل كان الهدف من إجراء هذا البحث.

** مشكلة البحث: إن الارتفاع المتزايد في استهلاك مصادر الطاقة التقليدية الناضبة و أهمها النفط والغاز الطبيعي المستخدمين في توليد الطاقة الكهربائية والحرارية لتغطية منطلبات تثنيل أنظمة تكييف الهواء والتبريد و المتزامن استتمارهما مـع نضوب بعض فئن آبارها وانخفاض كل من إنتاجها ومخزونها

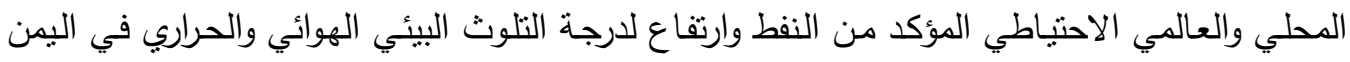

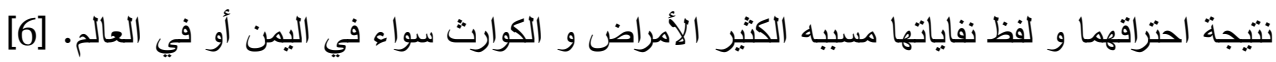


- البحث عن مصادر طاقية مجانية و متجددة و غير المدروسة في اليمن لغرض استثمارها أو لامجها

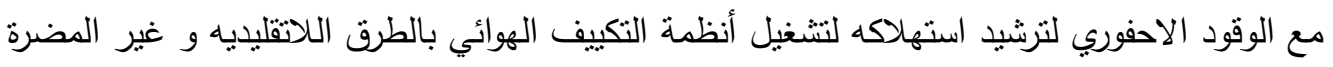
على البيئة البشرية و الطبيعة و تعمل بكلفة اقتصادية منخفضة.

- دراسة و تحليل مدى إمكانية استثمار طاقة مياه الأعماق الباردة الإقليمية اليمنية.

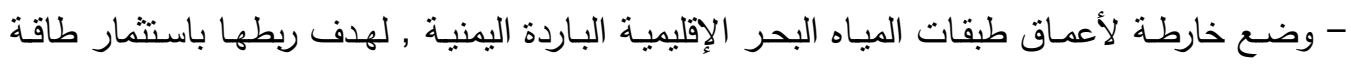

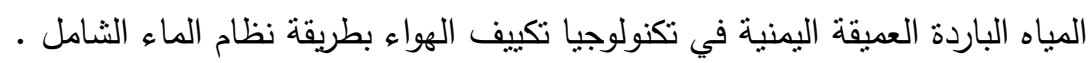

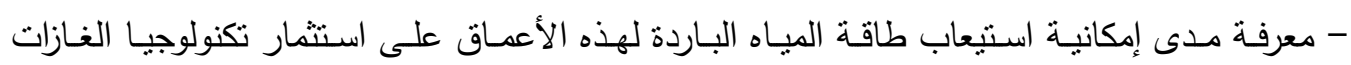
الهيدروبلورية في التكييف الهوائي و مقارنتها بطريقة نظام التكييف بالماء الثامل.

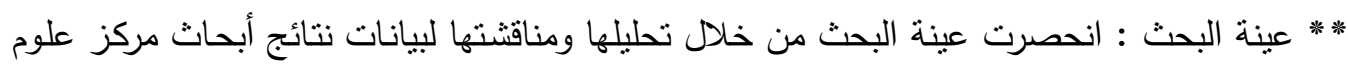

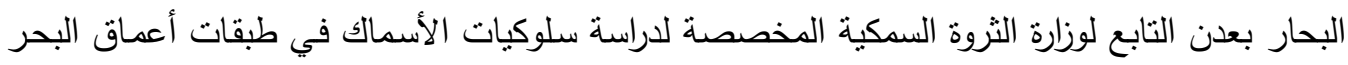

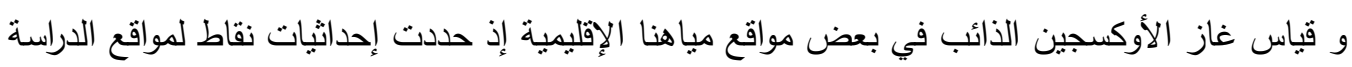

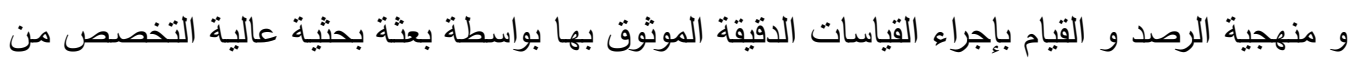

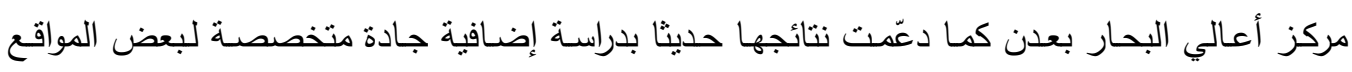

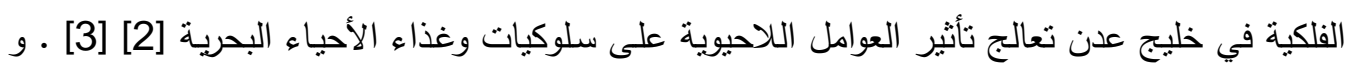

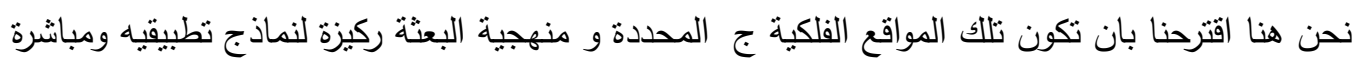
لمواقع أهداف هذا البحث و بياناته , لغرض جعل نتائج الدراسات متعددة الأغراض أكثر استثمارا من ون جهة والتقليص من الكلفة المالية لإجراء تلكك القياسات و متطلباتها التي تقدر بالملايين من الريالات

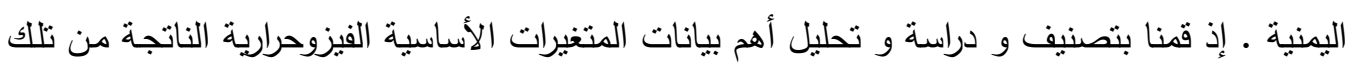

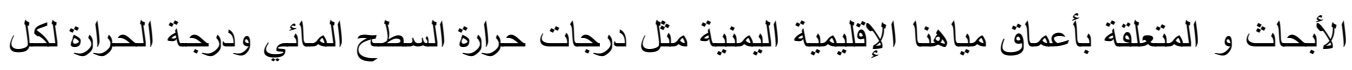

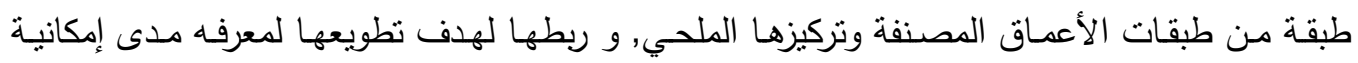

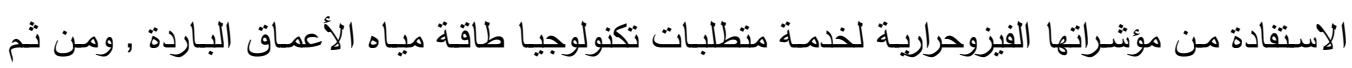

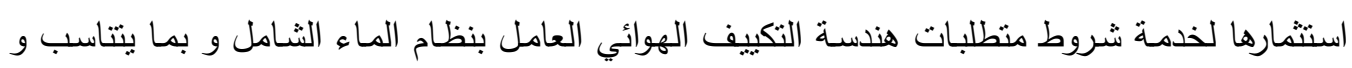
شروط البحث.

\section{* * المواقع المقترحة للبحث :}

اختيارنا لثلاثة مواقع لإجراء البحث , تمّ على أساس أن تكون هي نفس تلك المواقع التي اختيرت من

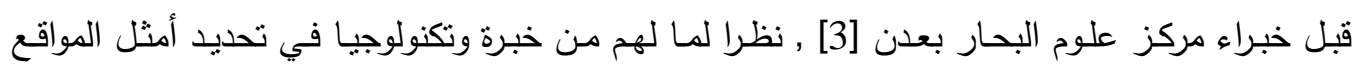

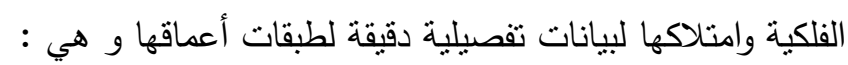

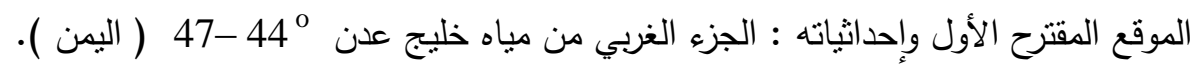

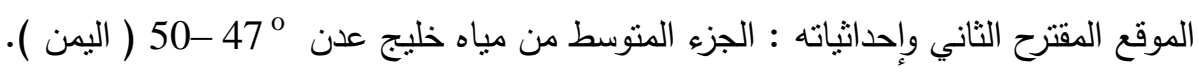


الموقع المقترح الثالث وإحداثياته : الجزء الثرقي من مياه خليج عدن 0 م-53-53 ( اليمن ).

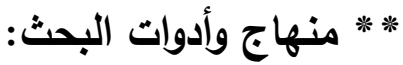

أرتكز منهج البحث على المحورين الميداني والنظري التحليلي الإحصائي للبيانات , متمدا في ذلك على نتائج و بيانات الدراسات و الإحصائيات و الأبحاث للمتغيرات الفيزوحرارية الجارية في أعماق مياه

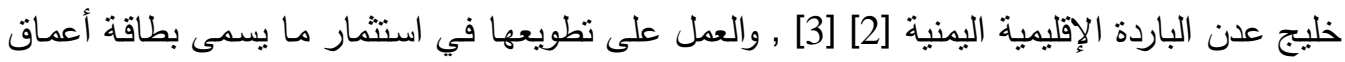

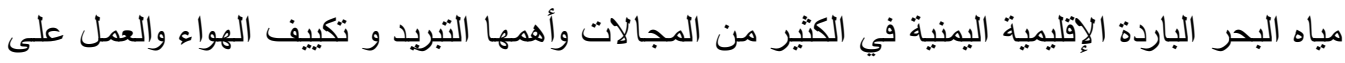

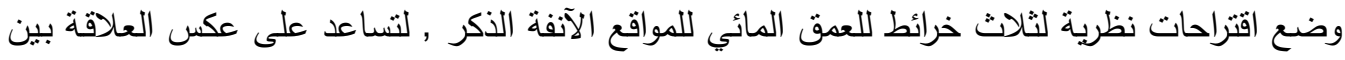

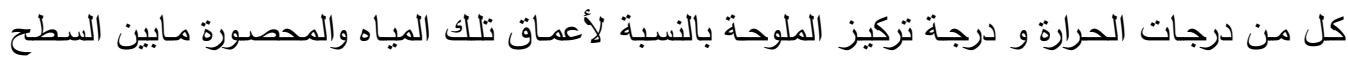

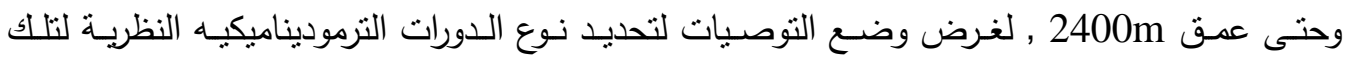

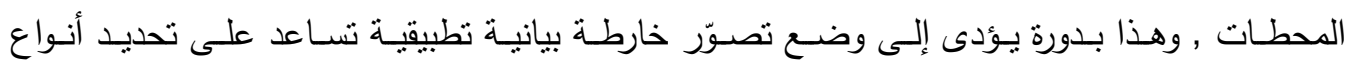
التكنولوجيا والوسيط التبريدي العامل التي يتتاسب تصميمها ومعرفه مدى إمكانية اكسيرجيا المياه الباردة

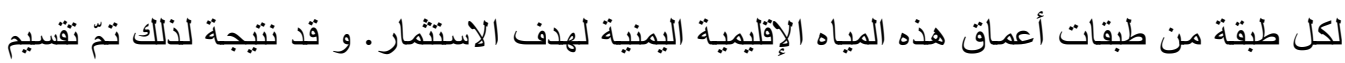
منهجية البحث إلى النقطتين الآتيتين:

\section{أولا: تحديد المواقع و دراسة عمق كل طبقة من طبقاتها.}

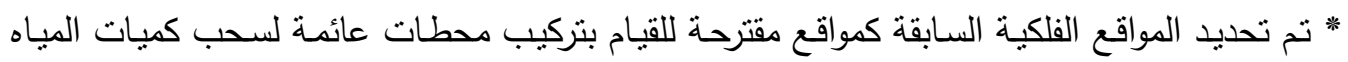

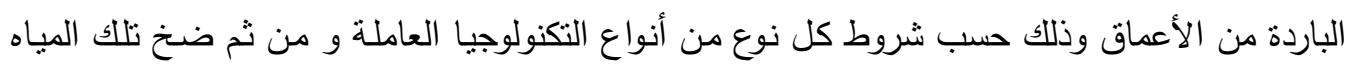
الباردة إلى البر لمعالجتها للاستثمار . * دراسة كل طبقة من طبقات أعماق مياه خليج عدن الباردة لتحديد علاقتها بكل درجة من درجات

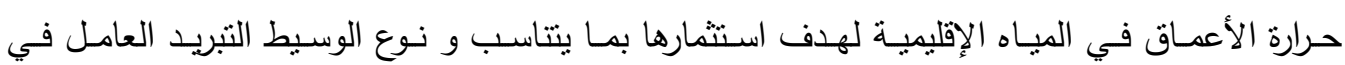

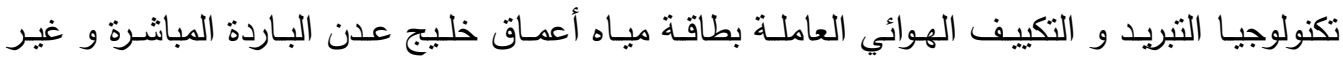

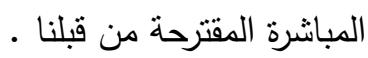

ثانيا : تحليل و تصنيف بيانات متغيرات درجات الحرارة و نسب تركيز الملوحة لكل العمق

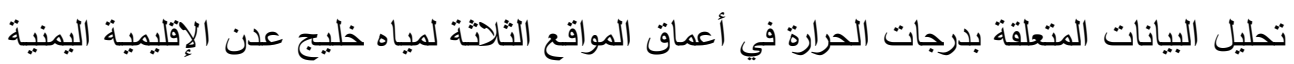

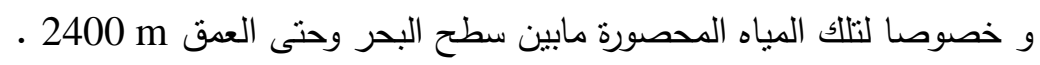
* تحليل البيانات المتعلقة بالتركيز الملحي في أعماق المواقع الثلاثة لمياه خليج عدن الإقليمية اليمنية

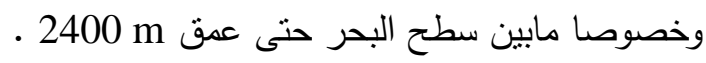

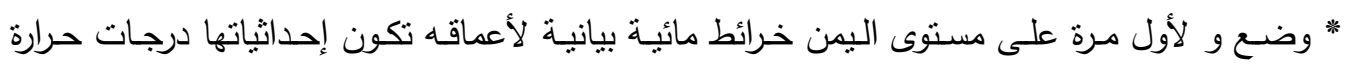

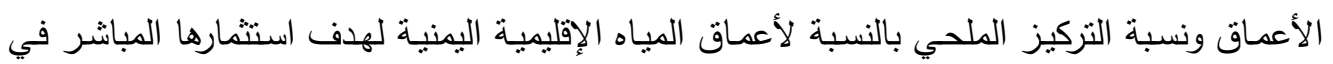


تكنولوجيا طاقة مياه الأعماق البـاردة أو اكسيرجيا الميـاه البـاردة و بشكل خـاص للعمق 2400m ,

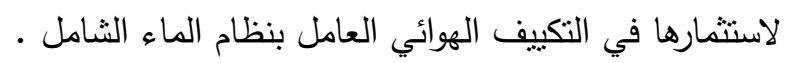

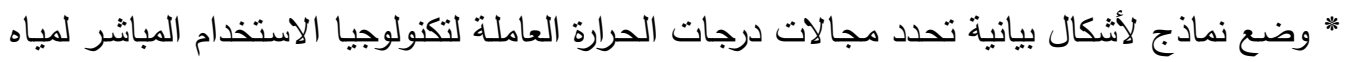

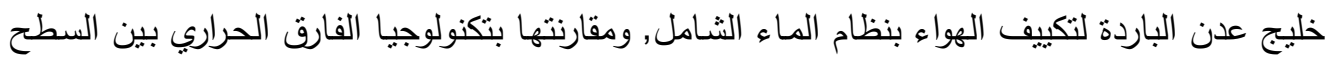
و العمق بالطريقة الهيدروبلوريه الكلورية أو الفريونية [7].

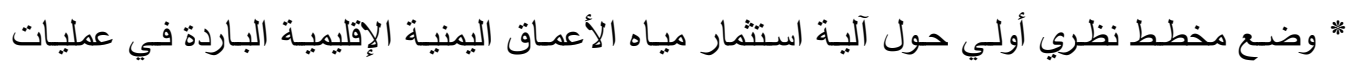
الاستخدام المباشر لمياه الأعماق الباردة في التكييف الهوائي بدلا عن تبريده بالطرق التقليدية باستخدام

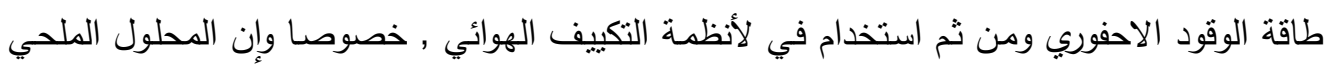
العامل فيها يتم تبريده بواسطة محطات نبريد اصطناعبة مركزيه تستهلاك كميات ضخمة من من مصادر الوقود الاحفوري الناضب.

لتغطية المنطلبات التقنية للنقاط السابقة لعمل محطات التبريد اللاتقليدية تمّ الاستفادة من نتائج البيانات

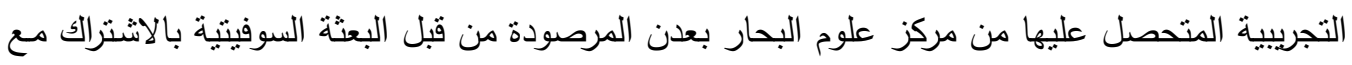

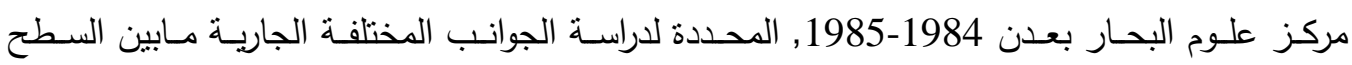
والأعماق m m 1000 ; 500 ; 200 ; 75 و معرفة متغيراتها الفيزوحرارية مثل درجات حرارة و الملوحة و كميات الغازات المذابة و التركيب الجيولوجي والكتافة النوعية في أعماق مياه خليج عدن في الأعوام ماتهات

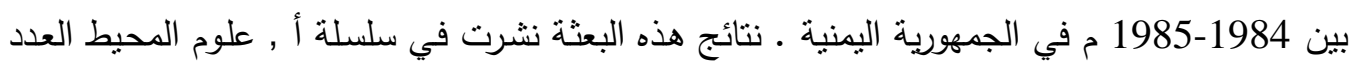

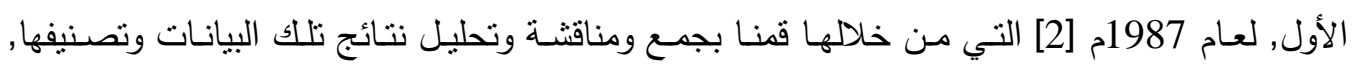

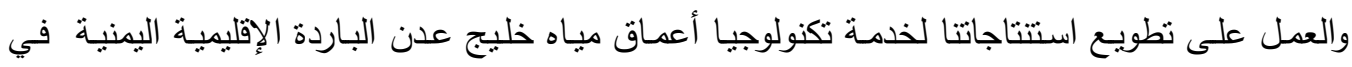

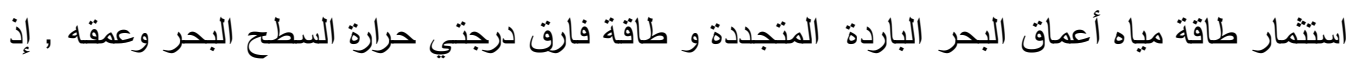

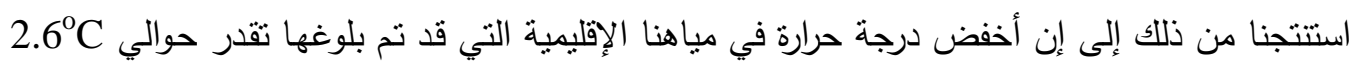
في الجزء الشرقي من خليج عدن عند موقع 50 - 53 , عند عمق يبلغ 2400m عن سطح مياه الخليج

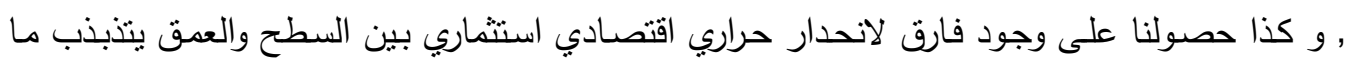

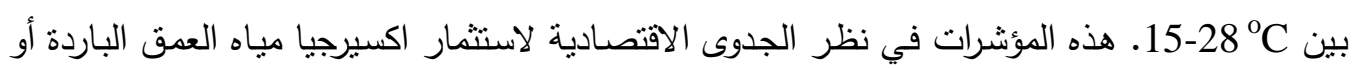

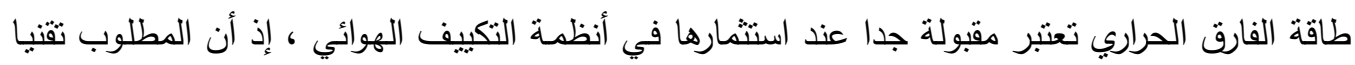

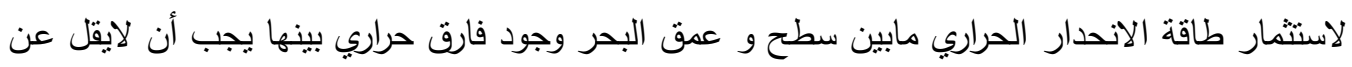
15º C الضرورية للاستثمار نجدها تتوفر و بنسبة نجاح مرتفعة في أعماق مياه خليج عدن الإقليمية اليمنية حسب تحليلنا للبيانات السابقة. 
تبين نتائج تحليل البيانات في الأشكال من 1 إلى 6 إلى الإمكانية التكنولوجية في الاستخدام المباشر

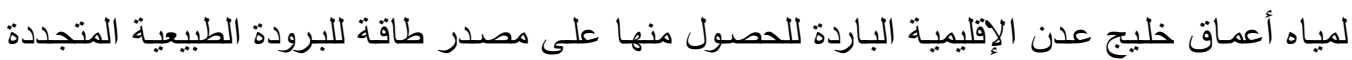

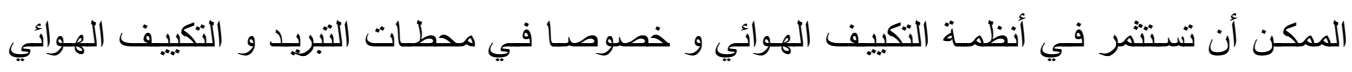

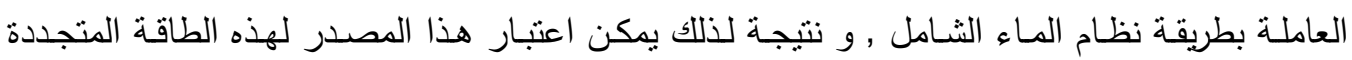
إضافة جديدة لتلك المصادر المتجدة المعروفة في اليمن كالطاقة الثمسية و طاقة الرياح و طاقة الكتل

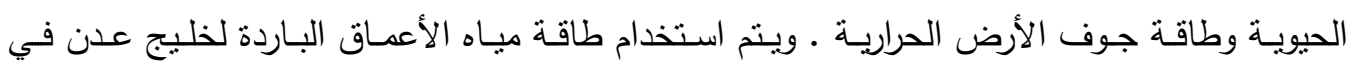

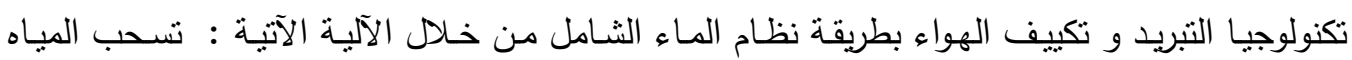

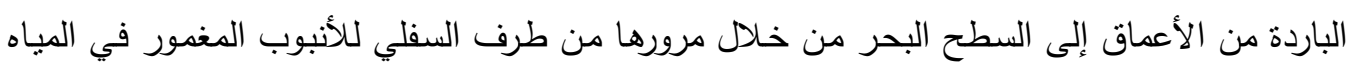

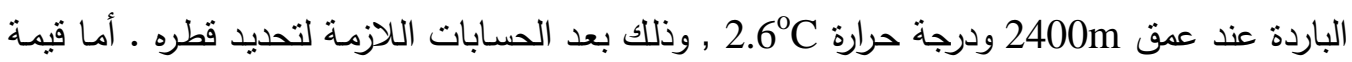
معامل النقل الحراري K فتحسب بمعلومة قيمة معامل التبادل الحراري \ـ من جهة العياه العميقة الباردة

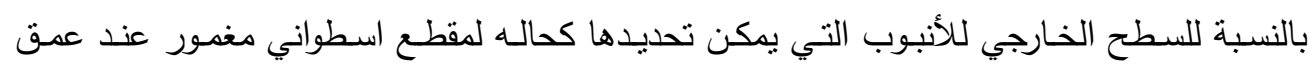

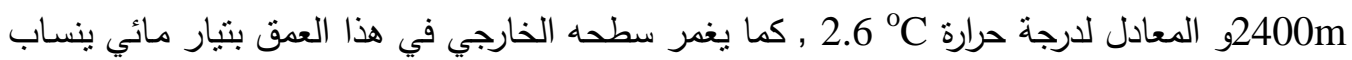

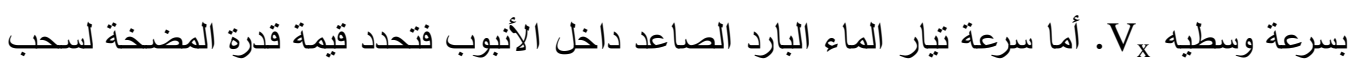

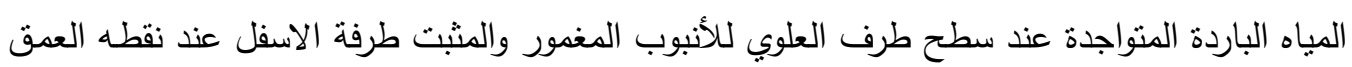

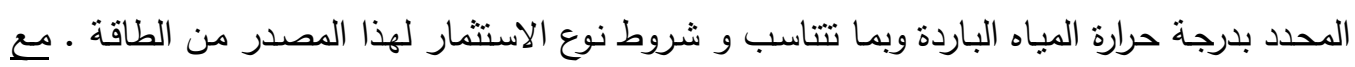

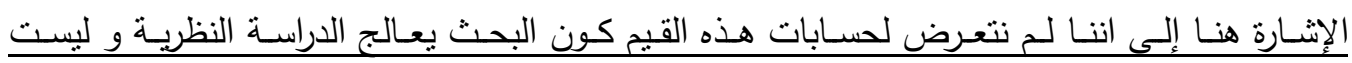

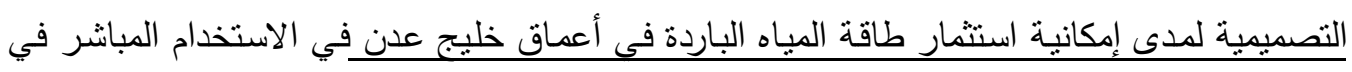

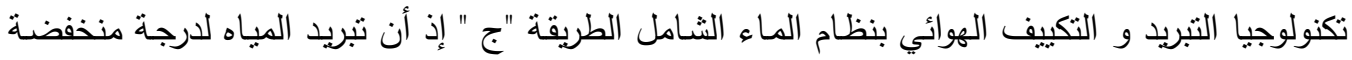

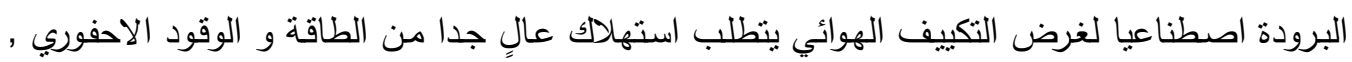

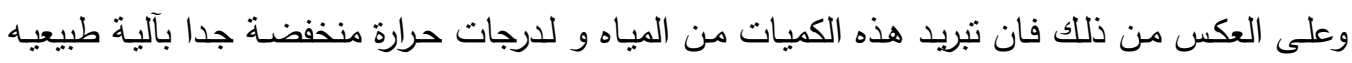

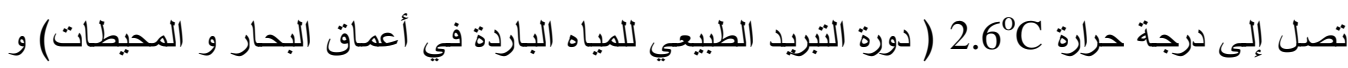
دون استهلاك أي مصدر من مصادر الطاقة التقليدية الناضبة لنتغغيل محطات التبريد المركزية لتبريد هذه الكميات من المياه اصطناعيا لنستخدم في التكييف الهوائي و حدوث أي تلوث حراري إضافي للبيئة

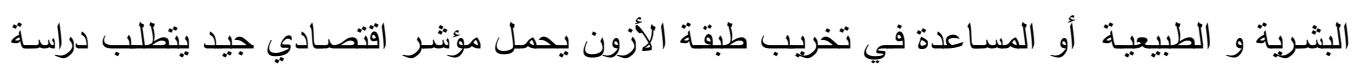
بعناية . و لعرض المقارنـة الاوليـة حول إمكانيـة استثمار المياه الإقليميـة اليمنية في خليج عدن في استخدام

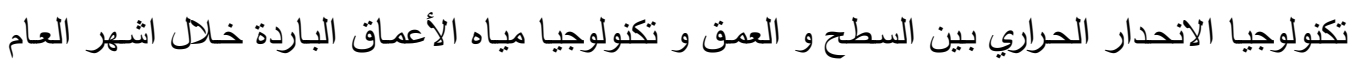

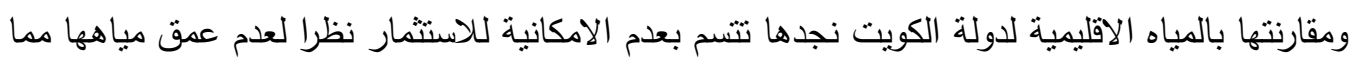
يعطي اليمن خصوصية في ذلك , كما تؤكده بيانات الثكل 1. 


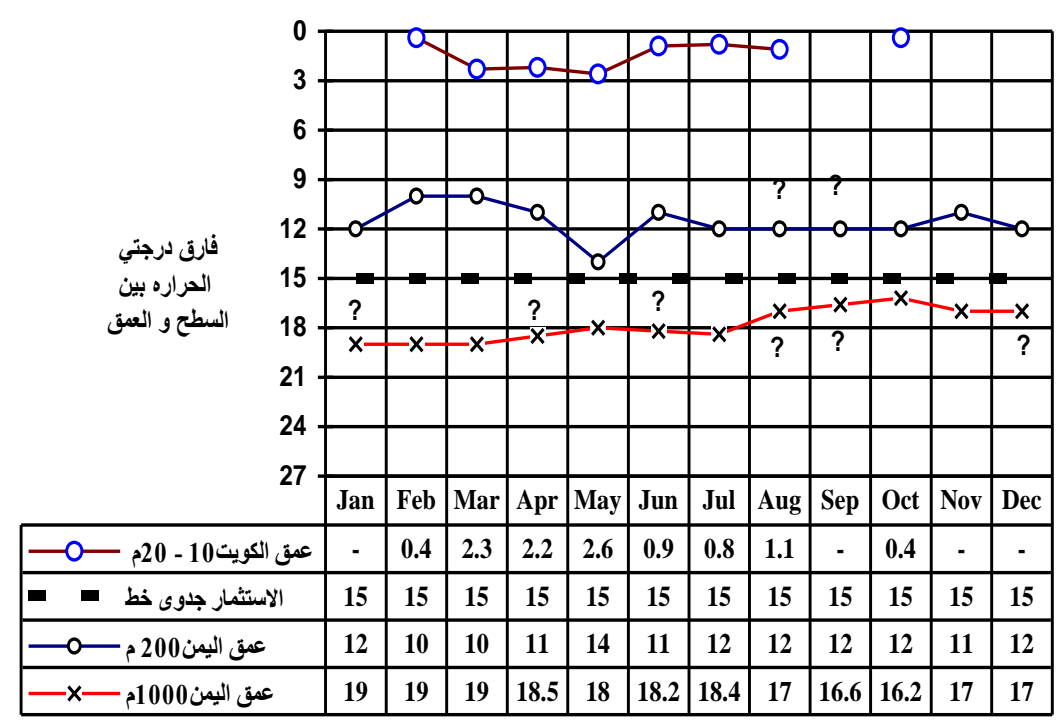

شكل رقم 1 خارطـة مائيسة تبين الفـارق درجتي الحرارة بين السطح وعمق البحر الإقليمي والمسـارات السنوية المتلى لاستثمار تكنولوجيا هذا الفارق حسب بيانات كل من شاطئ دولة الكويت و اعماق مياه

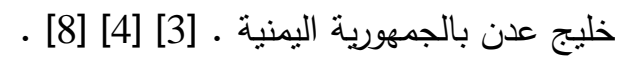

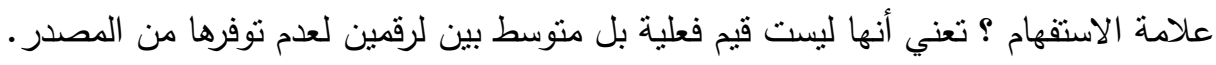
بيانات جدول رقم 1 التي قمنا بتصنيفها و تحليلها تبيّن العلاقة التي تربط بين درجتي الحرارة لكل من سطح وعمق مياه خليج عدن خلال أشهر السنة لعام 1985 - 1984 م , التي من خلالها أمكن استتناج

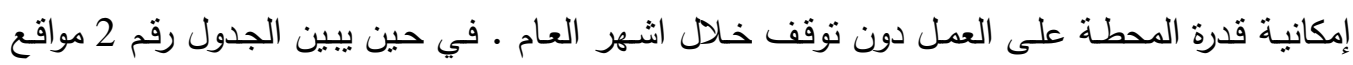

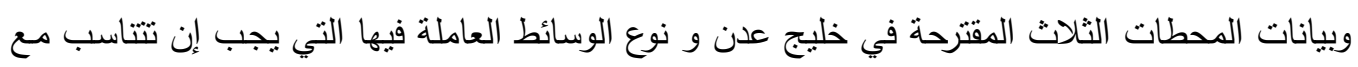

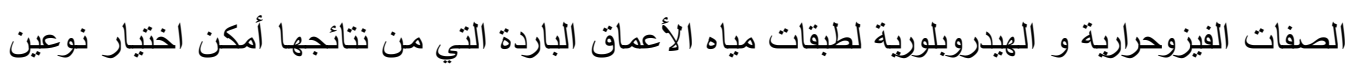
من التكنولوجيا : النوع الاولى تكنولوجيا الانحدار الحراري الهيدروبلوري في أعماق المياه الإقليمية اليمنية

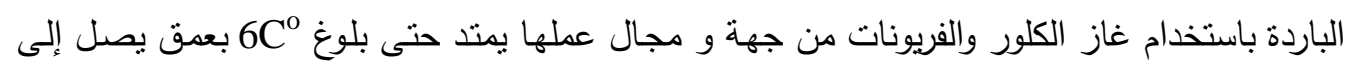

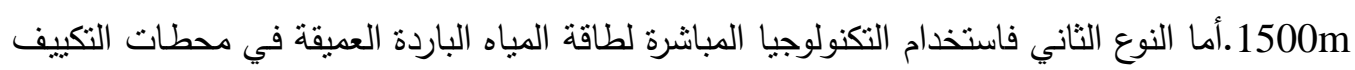

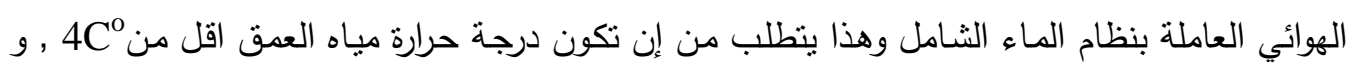

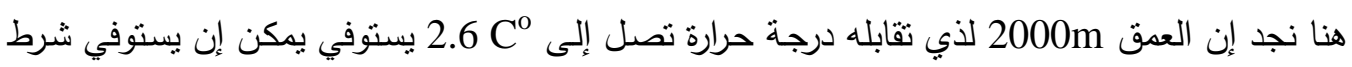

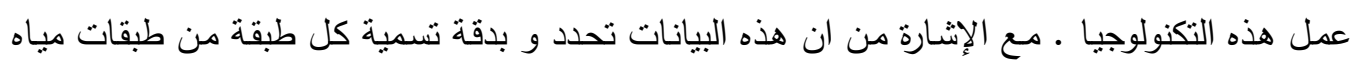

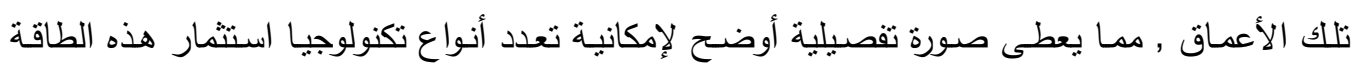

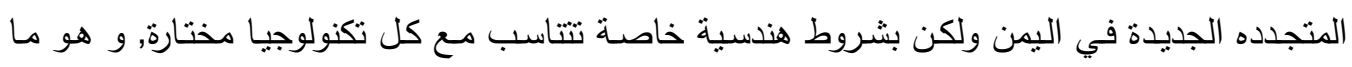


ينعكس بدورة إيجابا في الارتفاع المحسوس لمردود الفعل المفيد لإنتاجيه الدحطة المعنية, أكانت في

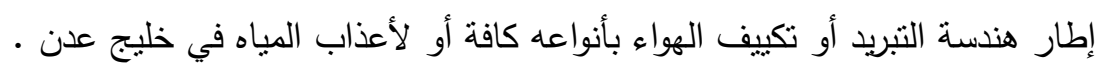

جدول 1 : العلاقة بين درجتي الحرارة لكل من سطح وعمق مياه خليج عدن و تغيراتها خلال كل شهر من أثهر السنة لعام 1985 - 1984 م . [ [2] + تحليل وتصنيف الباحث للبيانات ).

\begin{tabular}{|c|c|c|c|c|c|c|}
\hline عام الرصد & 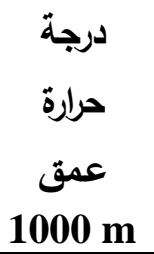 & $\begin{array}{c}\text { عرجة } 2 \text { عمقة } \\
\text { 500m }\end{array}$ & درجة حرارة & عرجة & سطحة حرارة & الشهر \\
\hline 1984 & 10.84 & 12.65 & 14.51 & 15.38 & $\begin{array}{l}30.09- \\
25.64\end{array}$ & أكتوبر \\
\hline 1984 & 10.5 & 12.9 & 14.46 & 15.71 & $\begin{array}{c}26.92- \\
25.59\end{array}$ & نوفمبر \\
\hline 1984 & - & 12.17 & 14.42 & 22.52 & $\begin{array}{c}26.74- \\
26.14\end{array}$ & ديسمبر \\
\hline 1985 & - & 12.43 & 15.03 & 21.58 & $\begin{array}{c}26.82- \\
25.28\end{array}$ & يناير \\
\hline 1985 & 8.24 & 12.43 & 15.26 & 22.02 & $\begin{array}{c}26.52- \\
24.7\end{array}$ & فبراير \\
\hline 1985 & 8.5 & 12.38 & 14.69 & 21.5 & $\begin{array}{c}26.42- \\
24.46\end{array}$ & مارس \\
\hline 1986 & - & 12.38 & 15.37 & 19.47 & $\begin{array}{c}28.79- \\
25.94\end{array}$ & ابريل \\
\hline 1986 & 9.2 & 12.26 & 15.25 & 19.86 & $\begin{array}{c}30.88- \\
29.67\end{array}$ & مايو \\
\hline 1986 & - & 12.10 & 14.00 & 17.29 & $\begin{array}{c}30.14- \\
21.06\end{array}$ & يونيو \\
\hline 1986 & 8.63 & 12.05 & 14.00 & 16.26 & $\begin{array}{c}30.07- \\
25.87 \\
\end{array}$ & يوليو \\
\hline
\end{tabular}

(2] [ + تحليل وتصنيف الباحث للبيانات )

جدول 2 العلاقة بين الصفات الفيزوحرارية لطبقات أعماق مياه خليج عدن باليمن و نوع وسبط العامل

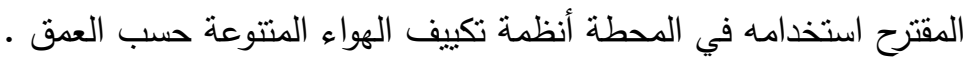

الموقع المقترح للمحطة الأولى وإحداثياتها: الجزء الغربي من مياه خليج عدن $44^{\circ}$-47 


\begin{tabular}{|c|c|c|c|c|c|c|}
\hline الفارق & اسم & نوع نوع & التركيز " & نوع الوسيط & درجة " & العمق " \\
\hline الحراري & الطبقة & حدود & الملحي & الهيدربلوري & الحرارة & مياه \\
\hline المكن & المائية & الأعماق & لمياه خليج & المقترح استخدامه & مياه & خليج \\
\hline استثماره & & & عدن من & في عمل محطة & الخليج & عدن \\
\hline$* * *$ & & & الألف & الأعماق" ",*"*" & عدن & بالأمتار \\
\hline 00.00 & م w & العلبا & 36.80 & - & 32.00 & السطح \\
\hline 00.00 & $r$ & & 36.00 & - & 25.00 & \\
\hline- & & السفلى ال & 36.20 & $\mathrm{Cl}_{2}$ & 25.00 & 20 \\
\hline 15.00 & ? & السنىلى & 35.60 & $\mathrm{R}-21-, \mathrm{R}-40$ & 17.00 & 125 \\
\hline - & مت تس & النواة & 35.80 & R-40,R-21 & 19.00 & 70 \\
\hline 18.00 & s & & 35.40 & $\mathrm{R}-22$ & 14.00 & 200 \\
\hline 15.50 & & السفا & 36.80 & R-22 & 16.5 & 150 \\
\hline 18.50 & ז & & 35.95 & R-22, R-124 & 13.5 & 450 \\
\hline- & مجب ح & النواة & 37.65 & R-21,R-22 & 17.50 & 500 \\
\hline- & $c \div<$ & 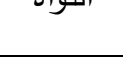 & 36.15 & $\mathrm{R}-142, \mathrm{R}-22$ & 13.50 & 900 \\
\hline 20.00 & & السفلى & 36.20 & R-12 & 12.00 & 1000 \\
\hline 22.00 & & 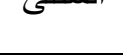 & 35.95 & $\mathrm{R}-12$ & 10.00 & 1100 \\
\hline 23.20 & مو & النواة & 35.80 & $\mathrm{R}-12$ & 9.80 & 1250 \\
\hline 26.00 & ? & المقارة & 35.10 & $\mathrm{R}-11$ & 6.00 & 1500 \\
\hline
\end{tabular}

الموقع المقترح للمحطة الثانية واحداثياتها : الجزع المتوسط من خليج عدن 50 - 57 -

\begin{tabular}{|c|c|c|c|c|c|c|}
\hline $\begin{array}{l}00.00 \\
00.00\end{array}$ & م س & العليا & $\begin{array}{l}36.45 \\
35.90\end{array}$ & $\begin{array}{l}- \\
-\end{array}$ & $\begin{array}{l}32.00 \\
25.00\end{array}$ & السطح \\
\hline $\begin{array}{c}- \\
16.00\end{array}$ & م س & السفلى & $\begin{array}{l}36.00 \\
35.40\end{array}$ & $\begin{array}{c}\mathrm{Cl}_{2} \\
\mathrm{R}-22\end{array}$ & $\begin{array}{l}24.00 \\
16.00\end{array}$ & $\begin{array}{l}20 \\
80\end{array}$ \\
\hline 18.00 & م ت س & النواة & $\begin{array}{l}35.70 \\
35.30\end{array}$ & $\begin{array}{c}\text { R-40,R-21 } \\
\text { R-22 }\end{array}$ & $\begin{array}{l}18.00 \\
14.50\end{array}$ & $\begin{array}{c}70 \\
250\end{array}$ \\
\hline $\begin{array}{l}16.00 \\
19.00\end{array}$ & م ت س & السفلى & $\begin{array}{l}36.10 \\
35.50\end{array}$ & $\begin{array}{c}R-22 \\
R-142 a\end{array}$ & $\begin{array}{l}16.00 \\
13.00\end{array}$ & $\begin{array}{l}200 \\
450\end{array}$ \\
\hline $\begin{array}{l}17.00 \\
20.00\end{array}$ & r & النواة & -------- & $\begin{array}{l}\text { R-22,R-21 } \\
\text { R-12, R-22 }\end{array}$ & $\begin{array}{l}15.00 \\
12.00\end{array}$ & $\begin{array}{l}450 \\
750\end{array}$ \\
\hline $\begin{array}{l}23.40 \\
21.60\end{array}$ & קب ح & السفلى & $\begin{array}{l}35.80 \\
35.50\end{array}$ & $\begin{array}{l}\text { R-22,R142a } \\
\text { R-12,R142a }\end{array}$ & $\begin{array}{l}8.60 \\
8.40\end{array}$ & $\begin{array}{l}1200 \\
1250\end{array}$ \\
\hline $\begin{array}{l}28.00 \\
28.20\end{array}$ & م ق & النواة & $\begin{array}{l}34.95 \\
34.95 \\
\end{array}$ & $\begin{array}{l}\mathrm{H}_{2} \mathrm{O}_{\text {c.w }} \\
\mathrm{H}_{2} \mathrm{O}_{\text {scw }}\end{array}$ & $\begin{array}{l}4.00 \\
3.80 \\
\end{array}$ & $\begin{array}{l}1800 \\
2000 \\
\end{array}$ \\
\hline
\end{tabular}

موقع المقترح للمحطة الثالثة وإحداثياتها : الجزء الثرقي من مياه خليج عدن 50 50 50

\begin{tabular}{|c|c|c|c|c|c|c|}
\hline $\begin{array}{l}00.00 \\
00.00\end{array}$ & مس س & العليا & $\begin{array}{l}35.30 \\
36.60\end{array}$ & - & $\begin{array}{l}31.00 \\
24.50\end{array}$ & السطح \\
\hline $\begin{array}{c}7 .--0 \\
15.50\end{array}$ & م س & السفلى & $\begin{array}{l}35.85 \\
35.45 \\
\end{array}$ & $\begin{array}{c}\mathrm{Cl}_{2} \\
\mathrm{R}-22 \\
\end{array}$ & $\begin{array}{l}24.00 \\
15.50 \\
\end{array}$ & $\begin{array}{c}50 \\
100 \\
\end{array}$ \\
\hline
\end{tabular}




\begin{tabular}{|c|c|c|c|c|c|c|}
\hline 100 & مت تس & النواة & 35.60 & R-21,R-22 & 17.00 & 150 \\
\hline 18.20 & & & 35.25 & $\mathrm{R}-12, \mathrm{R}-22$ & 12.80 & 250 \\
\hline 16.50 & مت تس & السفلى & 35.80 & R-21,R-22 & 14.50 & 250 \\
\hline 18.50 & & & 35.50 & R-142a,R-22 & 12.50 & 400 \\
\hline 18.00 & & النواة & 36.10 & R-124a,R-22 & 13.00 & 450 \\
\hline 20.50 & & & 35.75 & R-124a,R-12 & 10.50 & 950 \\
\hline 23.00 & & & 34.85 & R-124a,R-12 & 8.00 & 1200 \\
\hline 24.00 & r & & 34.80 & R-124a,R-12 & 7.00 & 1300 \\
\hline 28.00 & م ق & النواة & 34.82 & $\mathrm{H}_{2} \mathrm{O}_{\text {scw }}$ & 3.00 & 2000 \\
\hline 25.40 & & & 34.80 & $\mathrm{H}_{2} \mathrm{O}_{\text {scw }}$ & 2.60 & 2400 \\
\hline
\end{tabular}

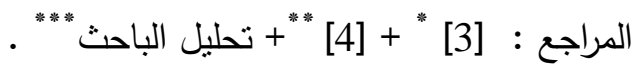

$$
\begin{aligned}
& \text { م س : مياه سطحيه , م ت س : مياه تحت سطحيه } \\
& \text { م ب ح : مياه البحر الأحمر , م ق : مياه قاعيّه. }
\end{aligned}
$$

: $\mathrm{H}_{2} \mathrm{O}_{\text {scw }}$, غياه أعماق خليج عدن الباردة المستخدمة مباشرة في المحطة العاملة : R

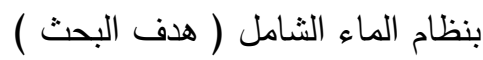

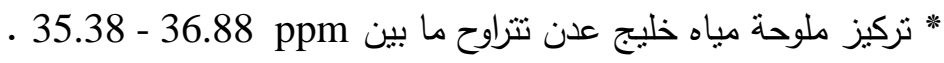

كما نشير من أن تحليل بيانات الجدول رقم 2 , تمت على اساس دراسة كل درجة من درجات الحرارة المنخفضة لكل طبقة من طبقات مياه أعماق خليج عدن بشكل منفرد وليس كفارق لانحدارها الحراري , و و

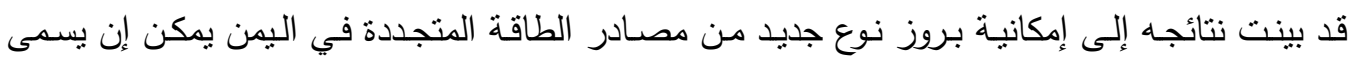

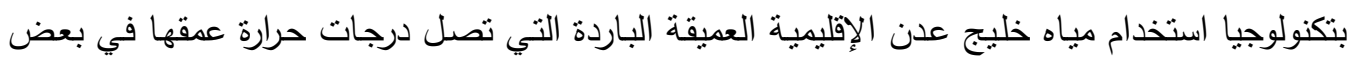

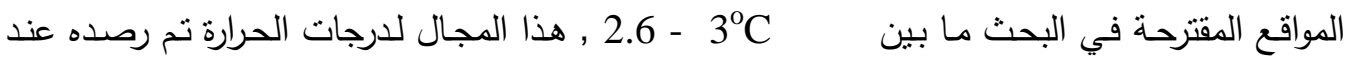
طبقات أعماق المياه التي تصل بين m 2400 - 2000 تحت سطح مياه خليج عدن [4]. ولأجل

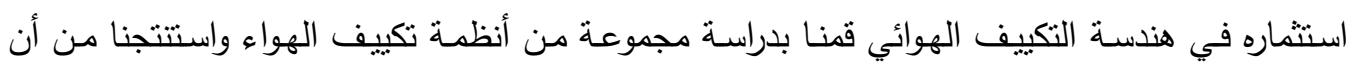
الاستثمار المباشر لمياهه الباردة كوسيط تبريد في تكنولوجيا تكييف الهواء يمكن أن يوصي باستخدامه

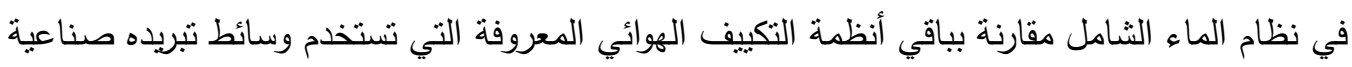
و تضر بالبيئه ـ إضافة إلى كون نظام الماء الثامل يحمل جدوى اقتصادية و بيئية جيده و يستخدم المياه البارده مباشرة كوسيط تبريد وهذا يحقق احد أهداف البحث ( شكل 2 )

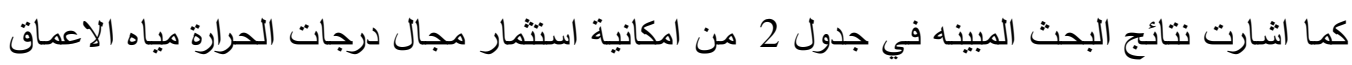

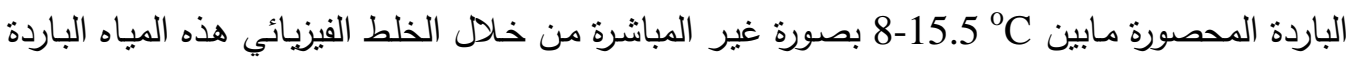

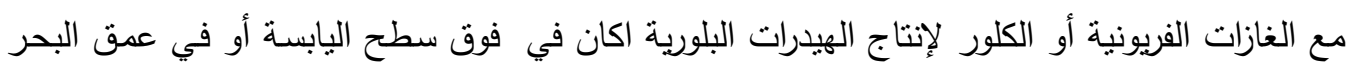
شرط أن تنوّفر الظروف الفيزيائية الخاصة لتوليد الهيدروبلورية وذلك لغرض تكييف الهواء ولإنتاج المياه 
العذبة من مياه خليج عدن • وتتكون آلية عمل هذه التكنولوجيا ( شكل 3 ) من سحب هذه المياه الباردة

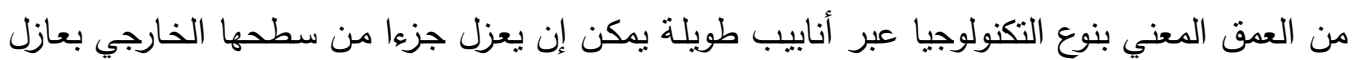

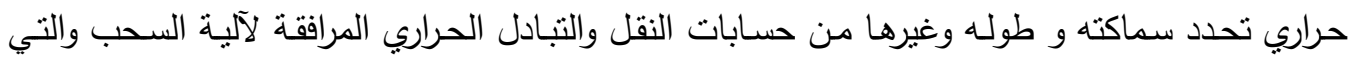

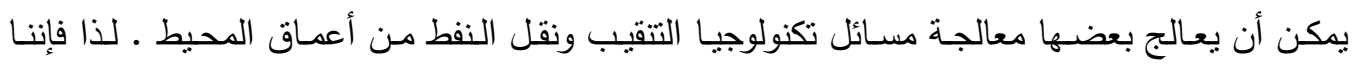
نوصي بضرورة إجراء أبحاث إضافية نتعلق بذلك عند وضع التصاميم التطبيقية.

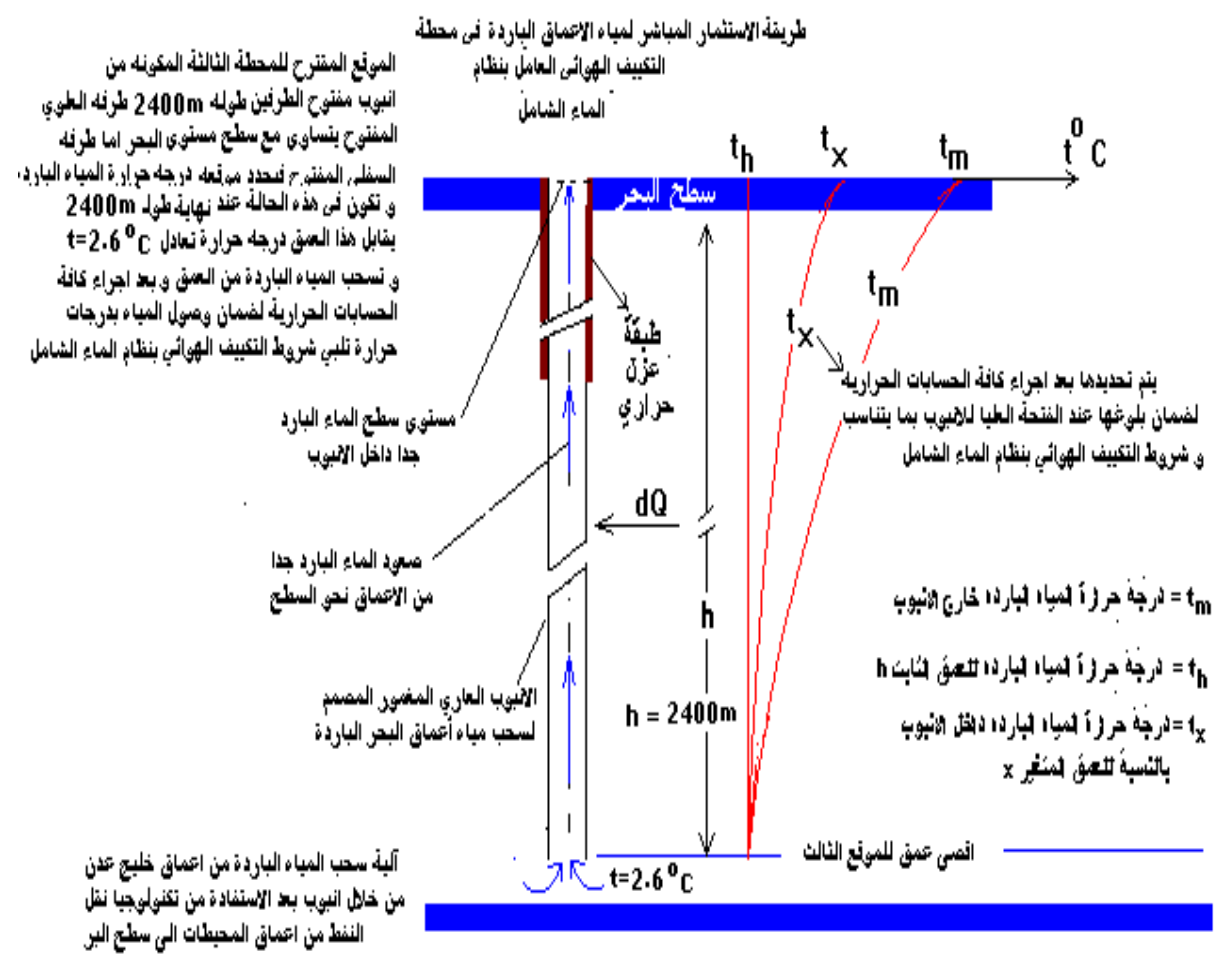

شكل رقم 2 مخطط أولـي ييبين آليـة سـحب الميـاه البـاردة مـن أعمـاق خليج عدن الإقليميـة اليمنيـة, لاستثمارها لتكييف الهوائي العامل بنظام الماء الثـامل ومنحنيات تغيرات درجات حرارة المياه الباردة اعنها

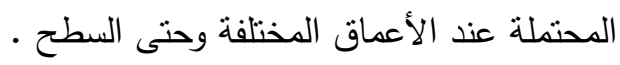




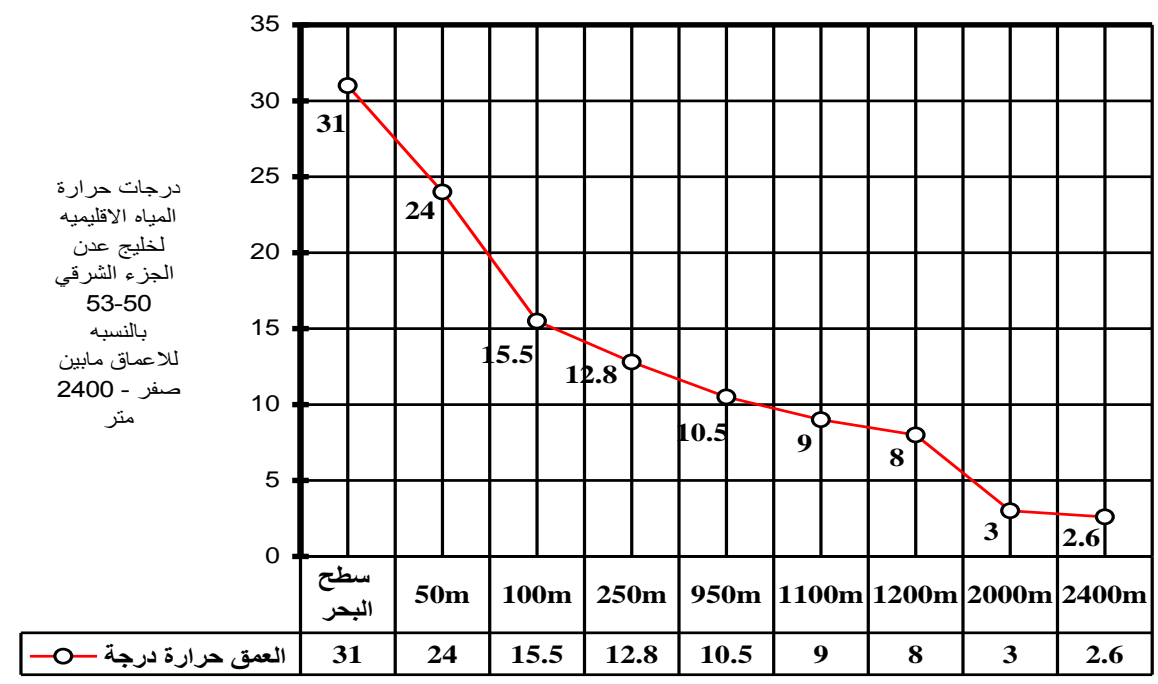

شكل رقم 3 الانحدار السلس لدرجات الحرارة بين السطح والعمق في الجزء الثرقي من المياه الإقليمية اليمنية لخليج عدن في اليمن و المحصورة بين سطح مياه خليج عدن و أعمق نقطة انخفاض 2400m. . [3] فيما يتعلق بدراسـة مسار العلاقة الانحدارية بين درجات حرارة السطح و الأعماق في خليج عدن فقد

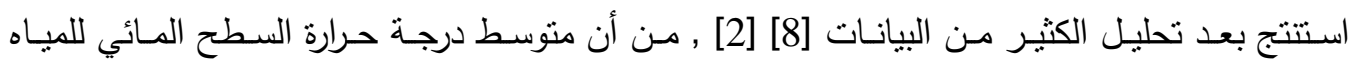

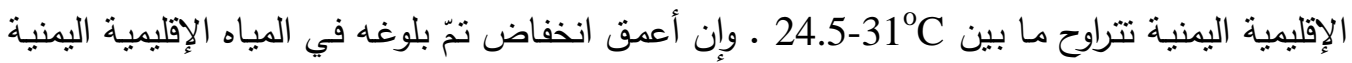

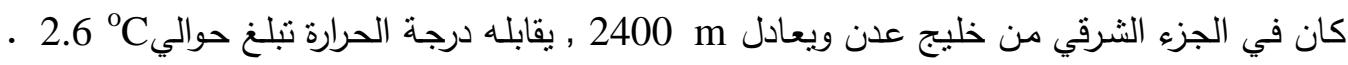

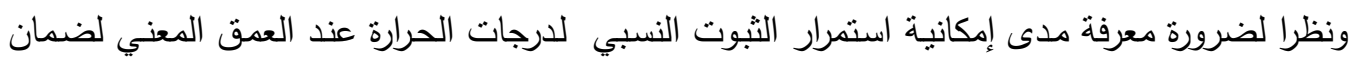
عمل انتاجية المحطة خلال العام فان بيانات الثكل 4 نتشير الى توفّر هذا الثرط لبعض المحطات

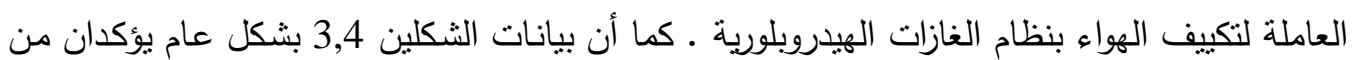
أن مجالات الانحدار لدرجات الحرارة بين طبقات المائية نحو العمق يقدم إمكانية أخرى للاستثمار طاقة باته

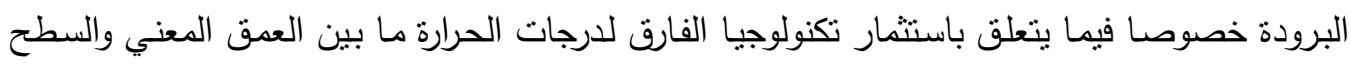

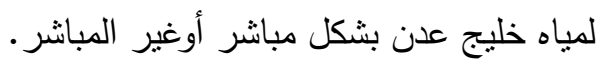

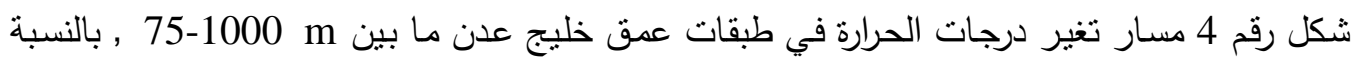

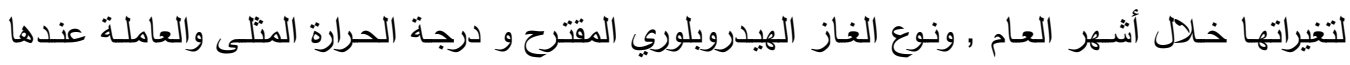
تكنولوجيا محطات الهيدروبلورية تبعا والثروط الفيزيائية البحرية الضرورية لتوليد الهيدرات البلورية. ملحوظة: التقاطعات المشار إليها بين نقاط مسار المنحنيات في الثكل رقم 4 نبين عدم توفر البيانات من المصدر في تلك الأشهر من سنوات الرصد و التسجيل. [3] [4] [2] 

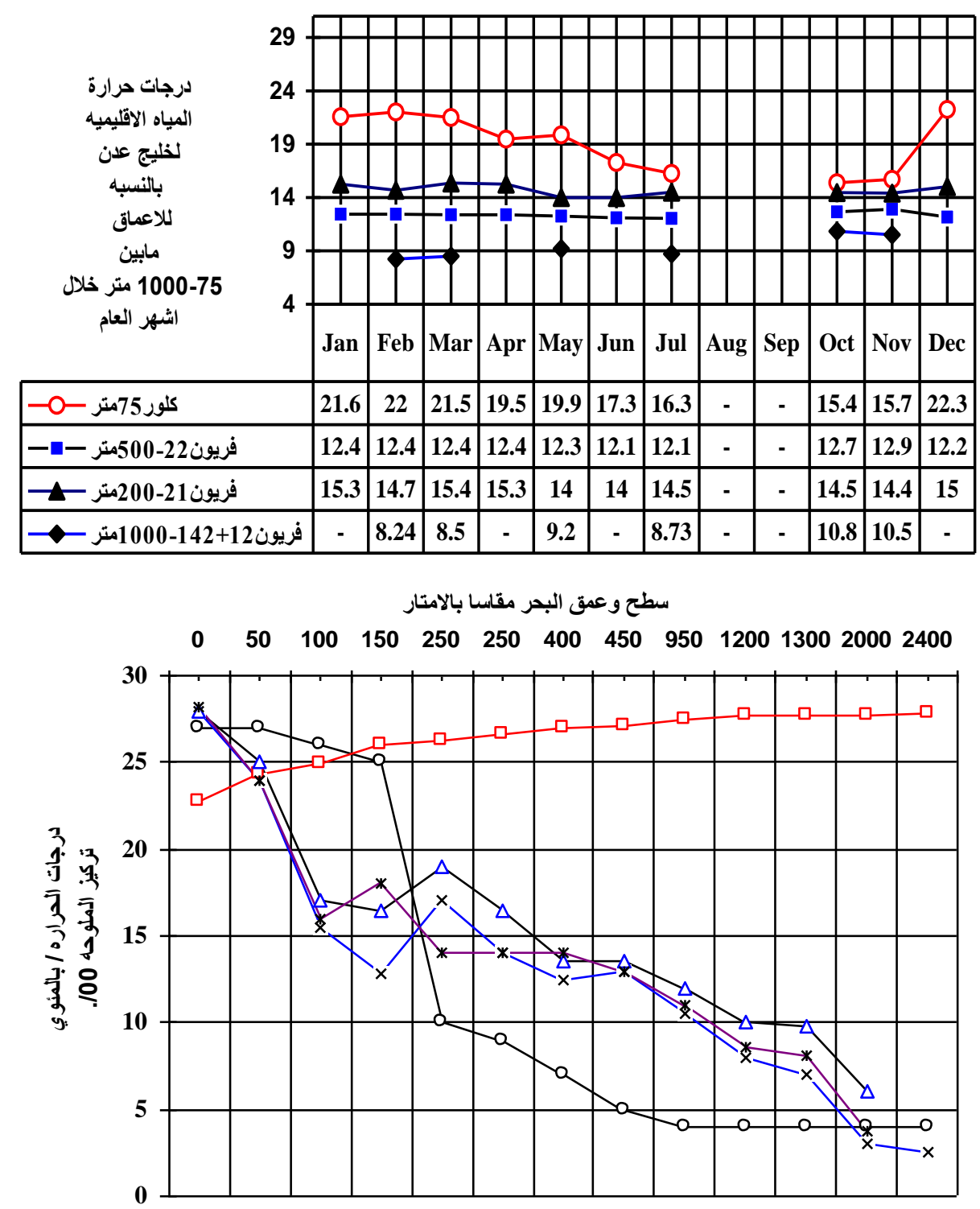

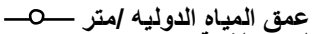

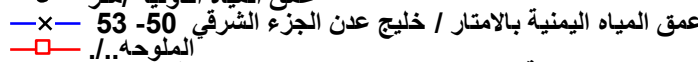

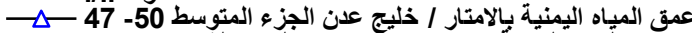

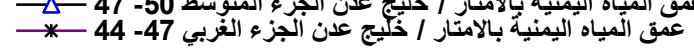

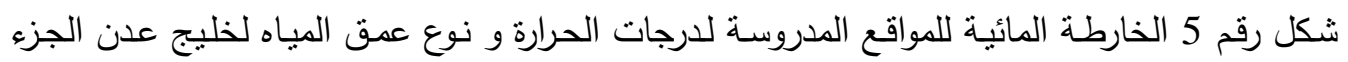
الغربي و المتوسط و الثرقي للمياه الإقليمية اليمنية [3] [4] [8]. 


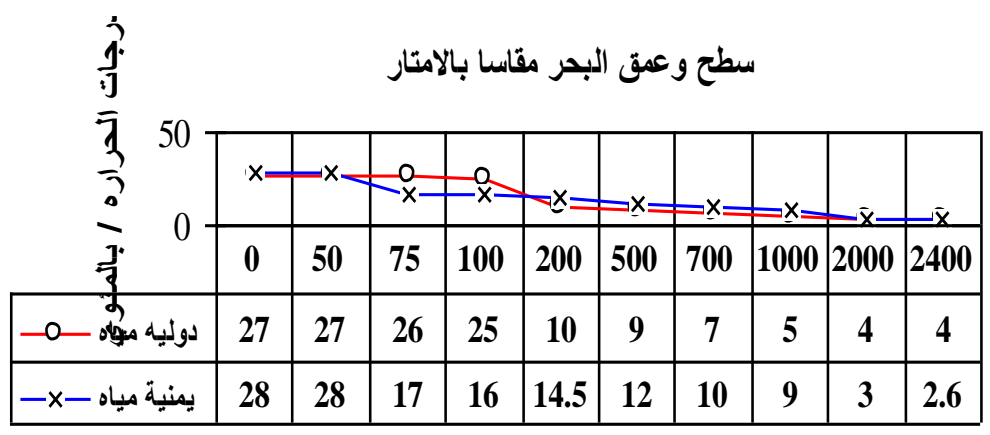

شكل 6 مقارنه بين التدريج لانحدار درجات الحرارة في أعماق طبقات المياه اليمنية الإقليمية في خليج عدن والمياه الدولية [3] [8].

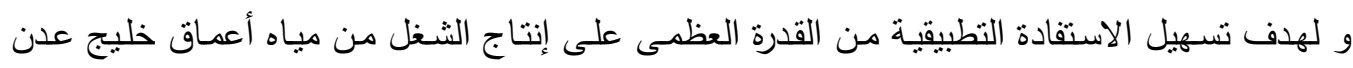

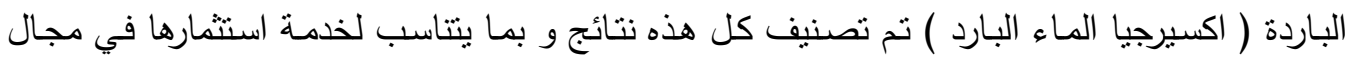

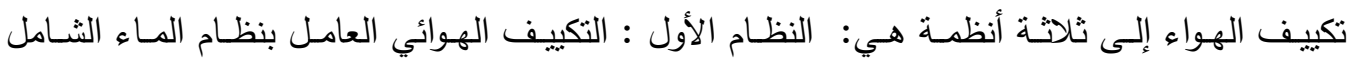
وباستخدام مياه الأعماق الباردة نموذج "ج" ( هدف البحث ) والنظام الثاني التكييف الهوائي العامل بغاز الكلور في المحطات الهيدرو البلورية الكلوريه و والنظام الثالث التكييف الهوائي العامل بغازات الثيات الفريون

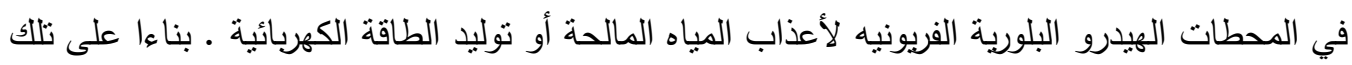

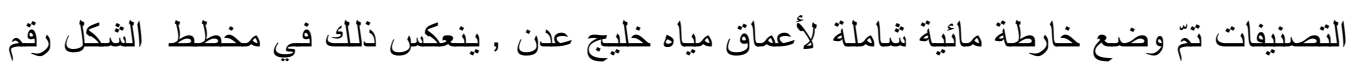
7 الذي يوضح المسارات و المواقع المنلى المقترحة لعمل كل نظام من أنظمة التكييف الهوائي المذكورة

سابقا . [4]

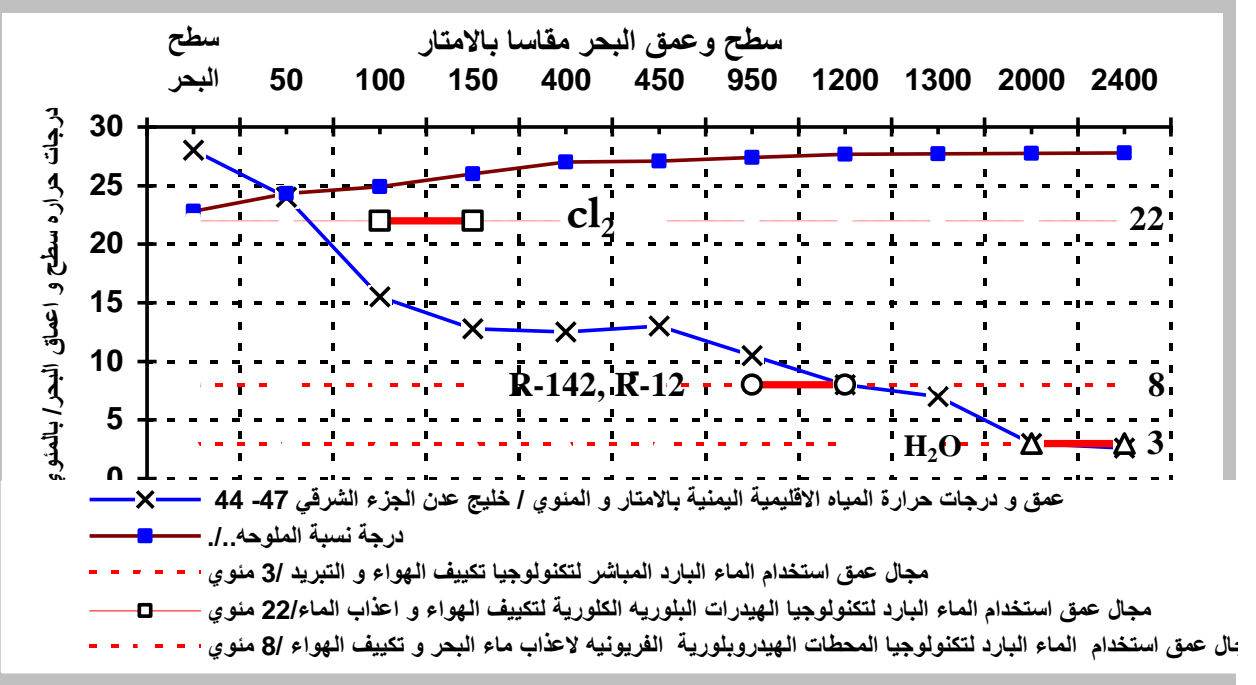

شكل 7 : علاقة نوع الوسيط بمدى تدريج انخفاض درجات الحرارة بالنسبة لعمق المياه الإقليمية اليمنية

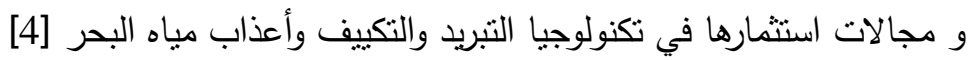


مع ضرورة الإثارة إلى نتائج و مناقثة تحليل بيانات شكل رقم 7 المدعمة بالبيانات التفصيلية التجريية

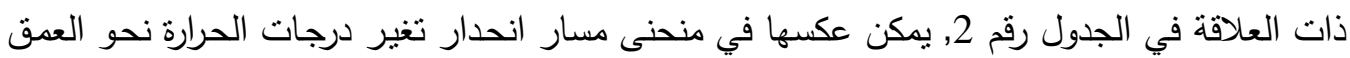

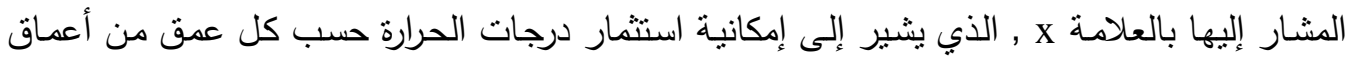

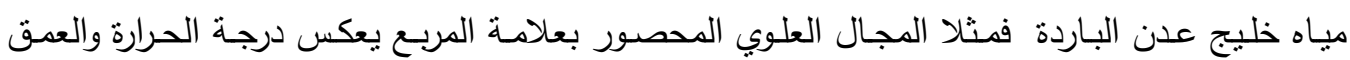

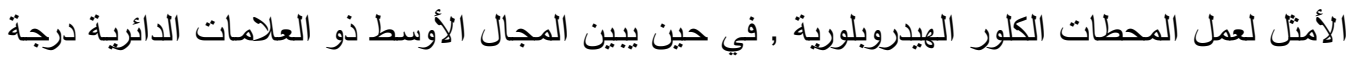

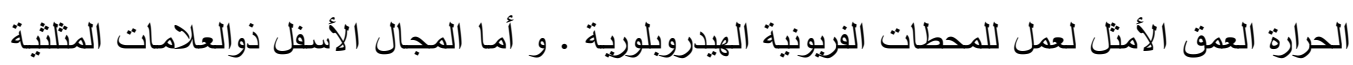
فيشير إلى إمكانية الاستخدام المباشر لهياه الأعماق البارد في تكنولوجيا نظام التكييف الهواء العامل

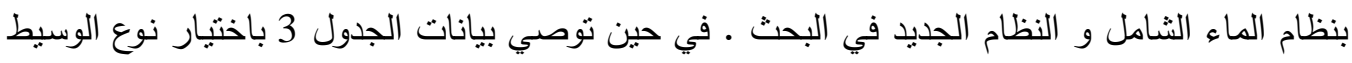

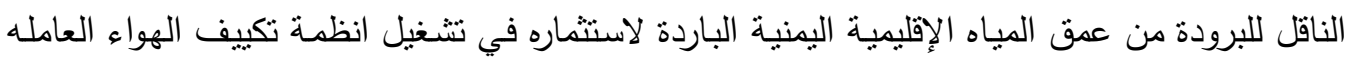
بالطريقة الهيدروبلورية أو بنظام الماء الثنامل.

جدول رقم 3 الوسيط الناقل للبرودة من عمق المياه الاقليمية اليمنيـة الباردة لاستثمارها في مجالات

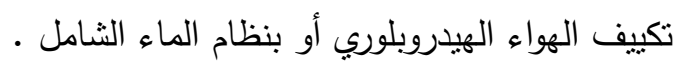

\begin{tabular}{|c|c|c|c|}
\hline اسم عمق المياه & استخدامها في مياه الأعماق الباردة المقرة & 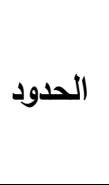 & بالأمتار \\
\hline مياه سطحيه & - & 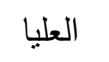 & سطح البحر \\
\hline مياه سطحية & $\mathrm{RF}+\mathrm{W} / \mathrm{R} 40-\mathrm{Cl}_{2}$ & السفلى & $100-50$ \\
\hline مياه تحت السطحية & $\mathrm{RF}+\mathrm{W} / \mathrm{R} 40+\mathrm{R} 22$ & النواة & $150-250$ \\
\hline مياه تحت السطحية & $\mathrm{RF}+\mathrm{W} / \mathrm{R} 40+\mathrm{R} 22$ & السفلى & $250-400$ \\
\hline مياه البحر الأحمر & $\mathrm{RF}+\mathrm{W} / \mathrm{R} 40+\mathrm{R} 142$ & النواة الن & $450-950$ \\
\hline مياه البحر الأحمر & $\mathrm{RF}+\mathrm{W} / \mathrm{R} 142+\mathrm{R} 12$ & 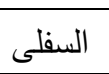 & $1200-1300$ \\
\hline المباه القاعيه & $\mathrm{RF}+\mathrm{W} / \mathrm{R} 21+\mathrm{R} 11$ & النواة & 2000 \\
\hline المياه القاعيه & $\mathrm{RF}_{\mathrm{c}} / \mathrm{H}_{2} \mathrm{O}_{\mathrm{scw}}$ & 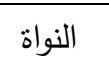 & 2400 \\
\hline
\end{tabular}

• تعني تكييف الهواء ينت بواسطة النظام الهيدروبلوري : RF

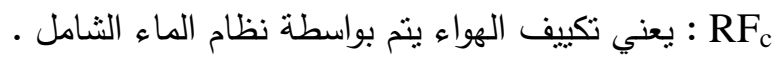

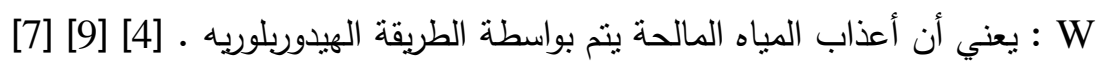
: $\mathrm{H}_{2} \mathrm{O}_{\text {scw }}$ R40 يعني الوسيط التبريد العامل هو غاز الكلور Cl R40/ Cl 


\section{* * النتائج و المناقثةة: *}

أولا : من تحليل نتائج الييانات بالنسبة لكل من درجات الحرارة و تركيز الملوحة و حدودها وكثافة ونوع

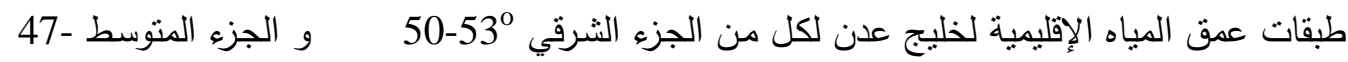

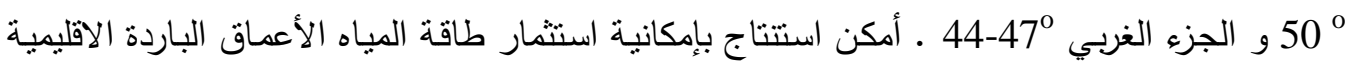

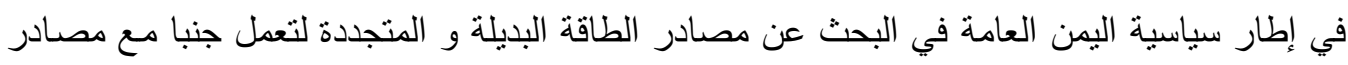

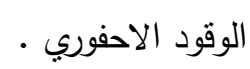

ثانيا : المتغيرات الفيزوحرارية في أعماق مياه الإقليمية الباردة في اليمن ترشحها لتكون من المناطق

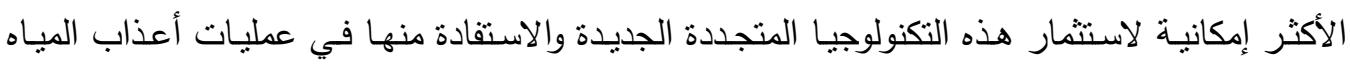

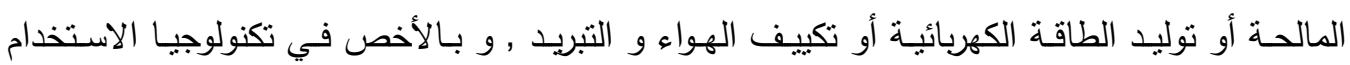

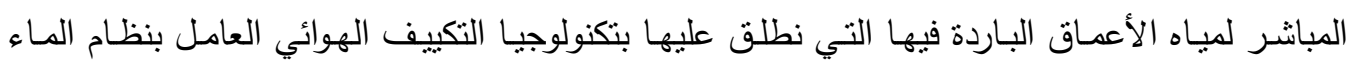
الثـامل المتجدد .إذ وجد أن اكسيرجيا المتر المكعب من المياه الباردة عند فارق الحياه الحدار حراري يقدر بحوالي 13 $1{ }^{\circ} \mathrm{C}$, يكنه أن يمنلك ( اكسيرجيا ) قدرة على إنتاج شغل يعادل

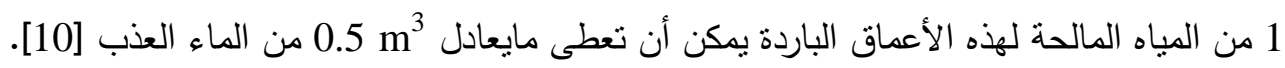

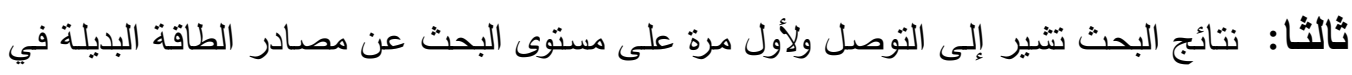
اليمن و إمكانياتها الاستثمارية من إدراج ما يسمى بطاقة اكسيرجيا مياه أعماق البحر الإقليمية اليمنية

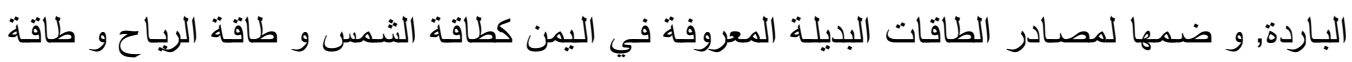
حرارة جوف الأرض و الكتل الحيوية . رابعا: يشير البحث إلى إمكانية استثمار التكييف الهوائي العامل على نظام الماء الثـامل , الذي من

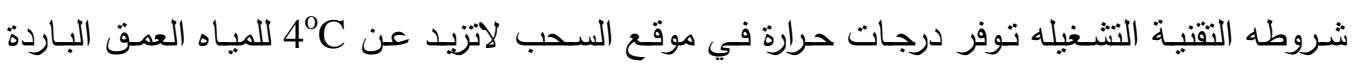
المستثمرة في هذه التكنولوجيا , وتؤكد نتائج تحليل البيانات السابقة بان : أعماق المياه الإقليمية اليمنية

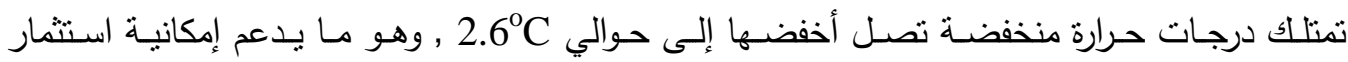
اكسيرجيا المياه الباردة في الأعماق اليمنية في إطار نظام التكييف الهوائي بنظام الماء الثامل.

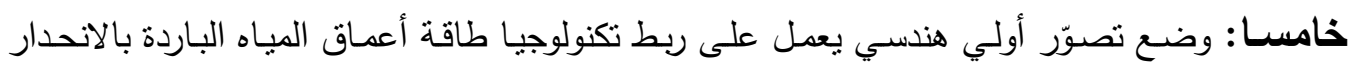
الحراري لمياه اليمن الإقليمية وبالأخص للمواقع الثلاثة المقترحة في خليج عدن , التي تبين مجالاتها

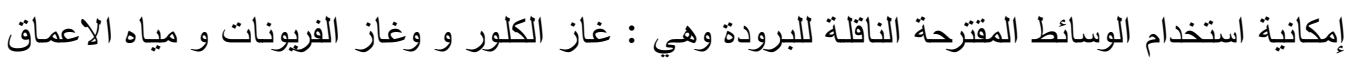
الباردة وبما يتتاسب وعمق موقع العمل و نوع المحطة و تكنولوجيتها أكانت هيدروبلوريه لأعذاب المياه

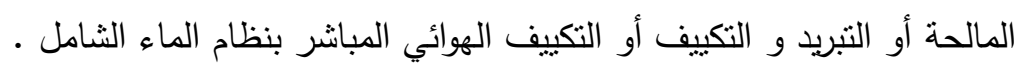


سادسـا: يعمل البحث على توفير و ترشيد الكثير من وقود التقليدي الناضب المستخدم في إنتاج

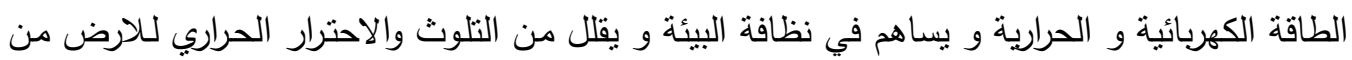
خلال خفض كميات الفريونات في محطات التكييف الهوائي , و يعمل على خفض رأس المال المخطط

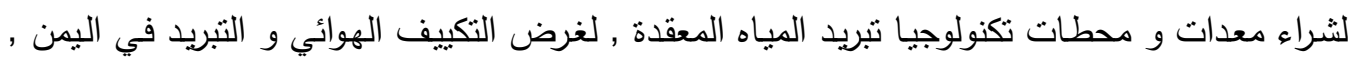
وهو ما ينعكس بشكل مباشر في إطالة عمر المخزون الاحتياطي والمؤكد من الغاز الطبيعي و النفط في لئرياه

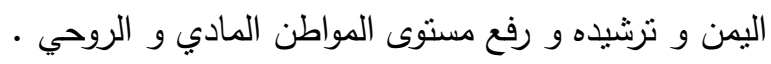

\section{** الخلاصـــة:}

تتشير نتائج تحليل البيانات الفيزوحراريـة النطبيقيـة المدرجة في البحث ولأول مره في إطلار أبحاث تكنولوجيا الطاقة المتجدة في اليمن من وجود إمكانية تقنية لاستثمار اكسيرجيا المياه الباردة في أعماق

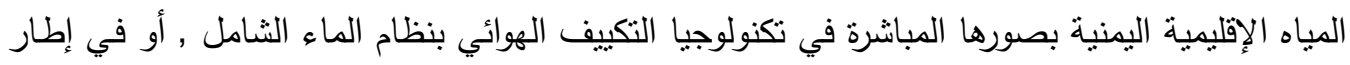
ما يسمى بتكنولوجيا الهيدرو بلوريه لأعذاب مياه البحر ونستخلص من البحث النقاط الآتية :

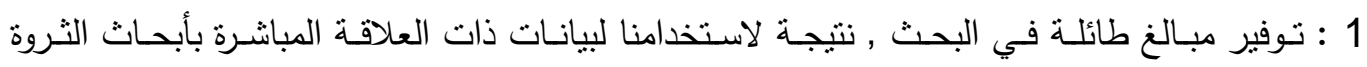
السمكية , وجعلها متعددة الأغراض والعمل على تطويعها و تصنيفها لانجاز أهداف البحث , وبأقل

كلفة اقتصادية ممكنة و بجدوى عاليه .

2 : تؤكد الدراسـة و لأول مره في اليمن , بإمكانيـة إدخال تكنولوجيا ميـاه الأعمـاق الإقليميـة البـاردة (

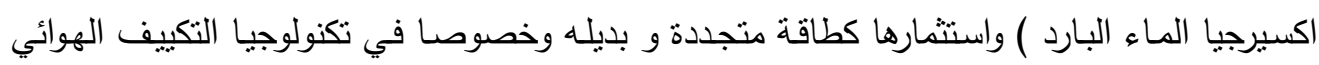

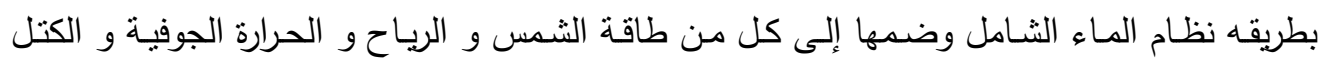

$$
\text { الحيوية المدروسة مسبقا. }
$$

3 : تمّ تحديد مواقع الفلكية لمصادر المياه الإقليمية العميقة الباردة اليمنية لهدف لإمكانية إنشاء محطات

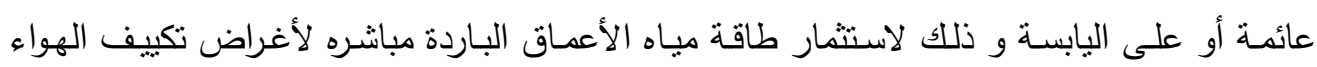
بنظام الماء الثامل. 4 : أخفض درجـة حرارة تقنيـة في ميـاه الأعماق الاقليميـه اليمنيـة بلغت 2004m من سطح البحر , بناءا على تحليلاتتا لبيانات أبحاث مركز علوم البحار بعدن.

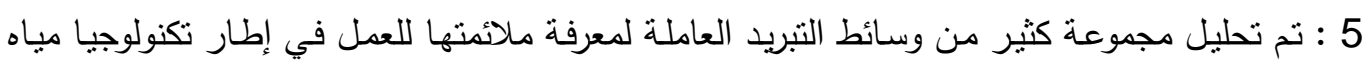
الأعماق الإقليمية الباردة في خليج عدن في الجمهورية اليمنية وقد اختير منها بالتحديد الوسائط الناقلة

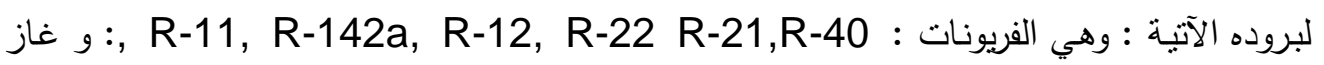

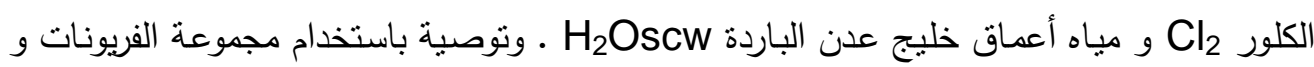

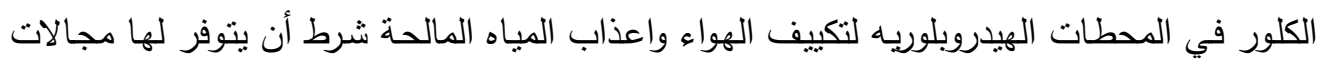


لدرجات الحرارة تتذبذب مابين 8-24º

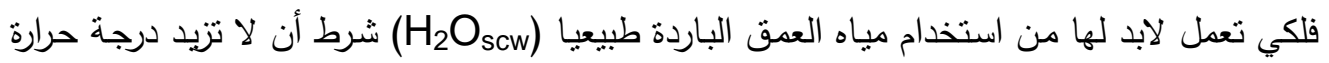

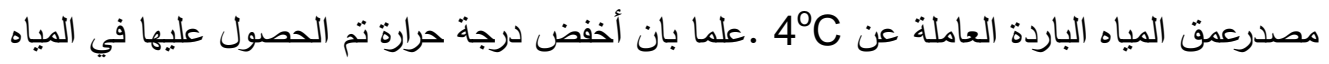
الإقليمية العميقة هي $2.6^{\circ} \mathrm{C}$

6 : وضـع خارطـة تحليلية للعمق المـائي الإقليمي اليمني , واستنتجنا منها إمكانيـة تشغيل التكنولوجيا

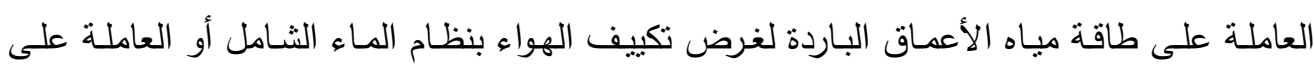

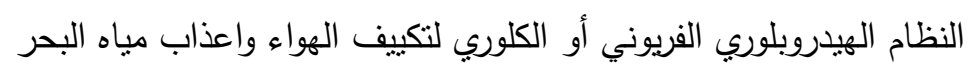

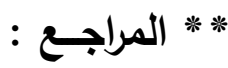

1.نيكولثن د.ج , (1971) • " الحسابات الحرارية لأنظمة ضخ مياه الأعماق في البحار الاستوائية ، باللغة

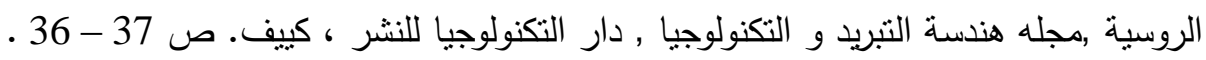

2. Saleh S.A., Subaih O.A., Gaddaf M., Spirdonov.V. ( 1987) " Study of Oceanographic Conditions in Composition of Water of PDRY For Years $1984-1985$. Sci .Invest . Gluf Aden-Series A., Oceanography No 1 .11.Hagen, A.W (1975) Thermal Energy From The Sea Noyes Data Corporation London, p.3.

3. صالح سالم عوض ( 1999 ) " تأثثير العوامل اللاحيويه على سلوكيات وغذاء الإحياء البحرية " أوراق الندوة العلمية حول الأفاق المستقبلية للاستخلال الأمثل للثروة السمكية و الإحباء البحرية المنعقدة - 16 13 يوليو بجامعة حضرموت للعلوم و التكنولوجيا.

4. بارعدي • ع ( 1990 ) " طرق حساب الخواص الترموديناميكية للوسـائط العاملـة في محطـات توليد

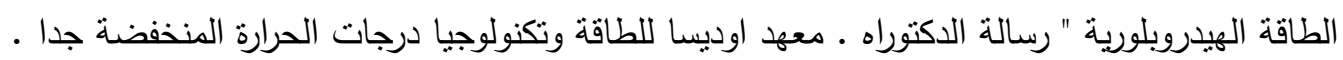

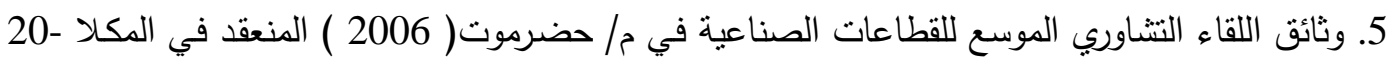

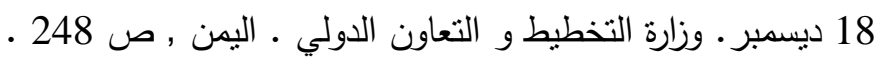

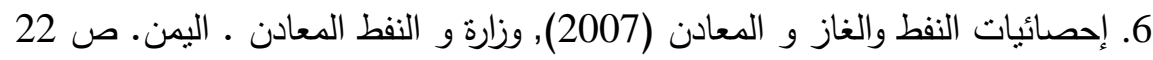

7. Nedostup V.I., Ba - Raadi A.A., (1989) “Thermodynamic cycles in solar energy for conditioning and sea water desalination. Proc of 6 th Conf. on Thermogrammetry and thermal engineering .Budapest, Hungary. P .521-524 .

8.عياش. سعود ( 1981) " نكنولوجيا الطاقة البديلة " سلسلة عالم المعرفة العدد 38 الكويت ص 721-73-724.

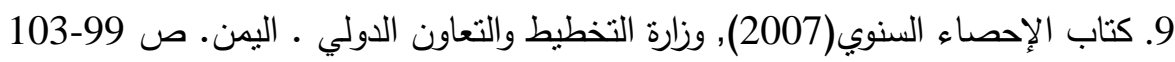
10. شولكين ب.ب ( 1963 ) " فيزيـاء البحار " باللغة الروسية , دار النشر أكاديمية العلوم السوفيتية . 